\title{
WestVirginiaUniversity
}

THE RESEARCH REPOSITORY @ WVU

Graduate Theses, Dissertations, and Problem Reports

2015

\section{Facial Planes as Landmarks for Diagnosis and Treatment Planning}

Jennifer Tomblyn

Follow this and additional works at: https://researchrepository.wvu.edu/etd

\section{Recommended Citation}

Tomblyn, Jennifer, "Facial Planes as Landmarks for Diagnosis and Treatment Planning" (2015). Graduate Theses, Dissertations, and Problem Reports. 6816.

https://researchrepository.wvu.edu/etd/6816

This Thesis is protected by copyright and/or related rights. It has been brought to you by the The Research Repository @ WVU with permission from the rights-holder(s). You are free to use this Thesis in any way that is permitted by the copyright and related rights legislation that applies to your use. For other uses you must obtain permission from the rights-holder(s) directly, unless additional rights are indicated by a Creative Commons license in the record and/ or on the work itself. This Thesis has been accepted for inclusion in WVU Graduate Theses, Dissertations, and Problem Reports collection by an authorized administrator of The Research Repository @ WVU. For more information, please contact researchrepository@mail.wvu.edu. 


\title{
Facial Planes as Landmarks for Diagnosis and Treatment Planning
}

\author{
Jennifer Tomblyn D.D.S.
}

\section{A THESIS}

\author{
Submitted to: \\ The School of Dentistry \\ at West Virginia University \\ in partial fulfillment of the requirements \\ for the degree of \\ Master of Science \\ In \\ Orthodontics
}

Tim Tremont D.M.D., M.S, Advisor

Chris Martin, D.D.S., M.S.

Richard Jurevic, D.D.S., Ph.D

\author{
West Virginia University \\ Department of Orthodontics \\ Morgantown, West Virginia
}




\section{ABSTRACT}

\section{Facial Planes as Landmarks for Diagnosis and Treament Planning}

Jennifer Tomblyn D.D.S., Timothy Tremont, D.M.D.,M.S, Chris Martin, D.D.S., M.S., Richard Jurevic, D.D.S.,Ph.D.and Erdogan Gunel, Ph.D.

Background and Objectives: Diagnosing and treatment planning in contemporary orthodontics is based on comparing elements of craniofacial morphology to selected reference planes. Ideally, a valid reference plane should have good intra-individual reproducibility, low inter-individual variability, and good reliability. The aim of this study was to determine 1.) the reliability and reproducibility of FALL and Glabella Vertical as reference planes 2.) if Glabella Vertical can be used as a frontal reference plane and 3.) if NHO is affected by varying chin positions. Methods: Part 1) 3 judges measured 4 variables (F, FC, G, and GC) on 23 subjects at T1 and T2. Part 2) 105 lateral cephalograms were traced and measured to find the location of GALL to glabella. Part 3) 26 judges (13 orthodontists and 13 non-orthodontists) determined NHO in 3 chin positions (class I, class II, and class III). Results: Part 1) There were significant differences between mean levels of measurements between raters. The inter-rater reliability coefficient was moderate-good at T1 and T2 and the intra-rater reliability coefficient was good between T1 and T2. Part 2) GALL was not always located at glabella. Part 3) There were significant differences between angle means at class I, II and III. Tukey Kramer showed differences between class II and III but not between class I and II and class I and III. There were no differences in NHO between males and females or orthodontists vs non-orthodontists. Conclusion: FALL and Glabella Vertical are reliable and reproducible reference planes. Glabella Vertical can be used as a frontal plane for diagnosis and treatment planning. Judging NHO is under the influence of AP chin position; however, this influence is not clinically significant. 


\section{TABLE OF CONTENTS}

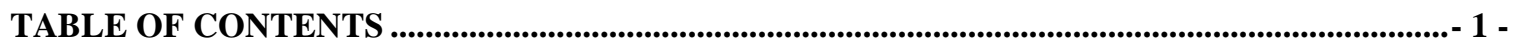

LIST OF TABLES ................................................................................................................................................ 2 -

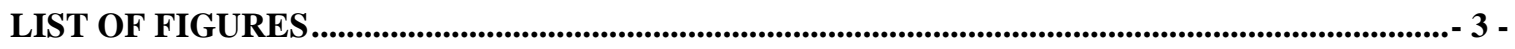

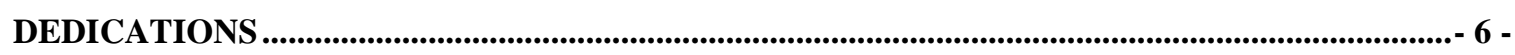

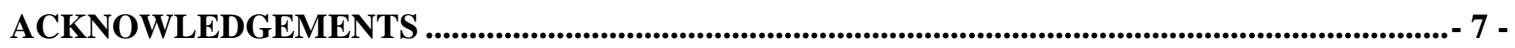

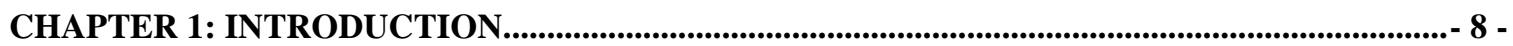

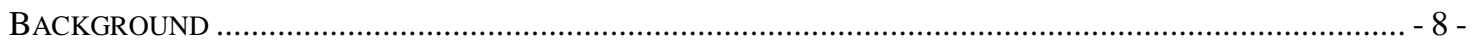

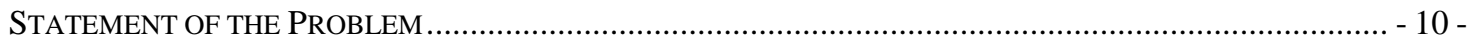

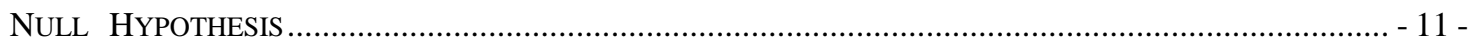

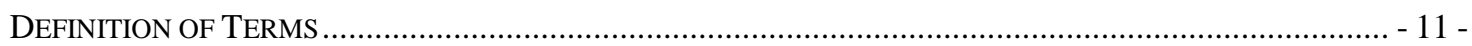

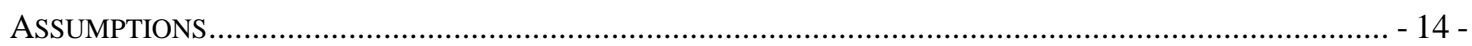

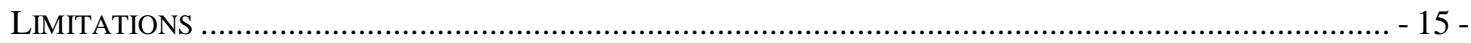

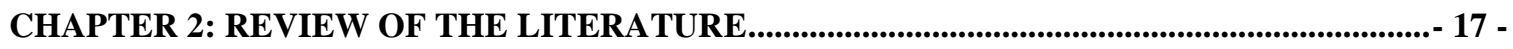

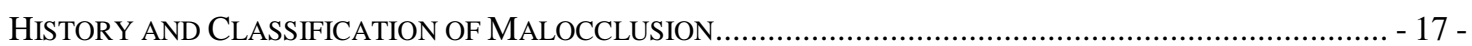

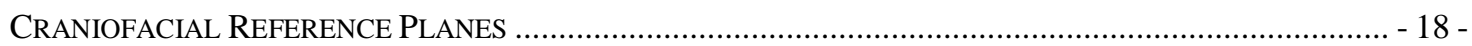

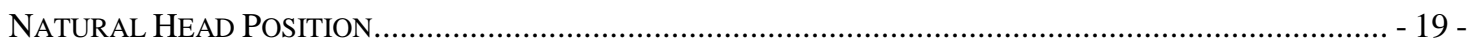

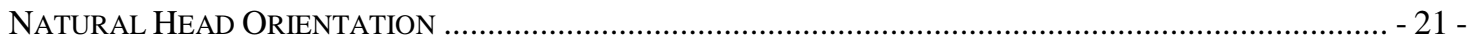

RELATIONSHIP OF NATURAL HEAD POSITION TO CRANIOFACIAL MORPHOLOGY .................................. - 21 -

DETERMINING NATURAL HEAD ORIENTATION 3-DIMENSIONALLY …….......................................... - 22 -

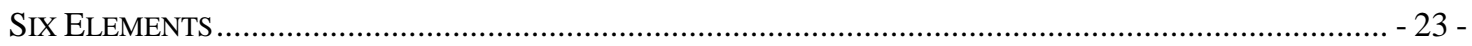

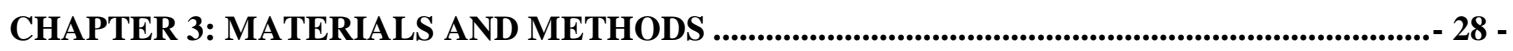

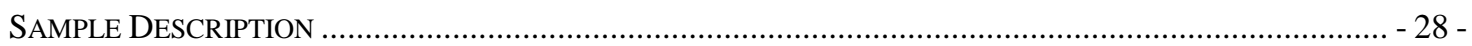

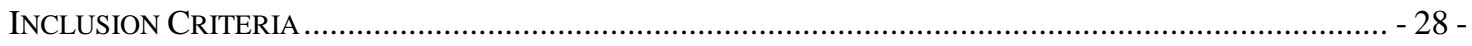

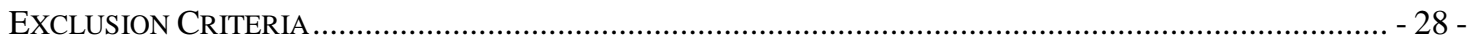

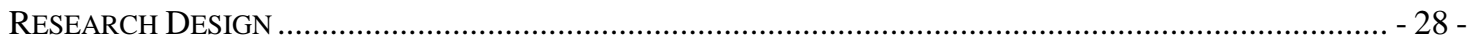

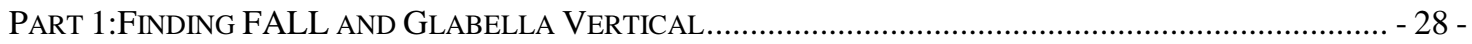

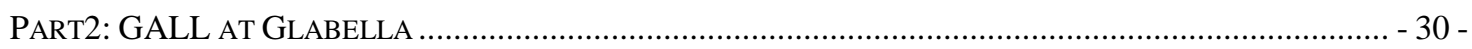

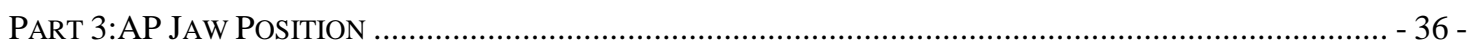

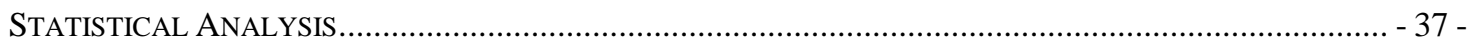

CHAPTER 4:RESULTS ..........................................................................................................................- 38 -

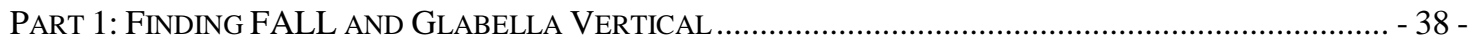

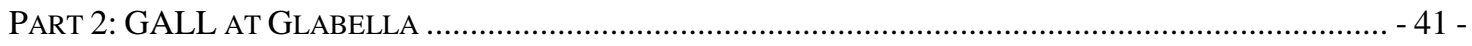

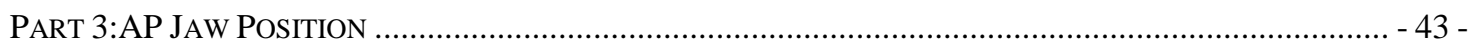

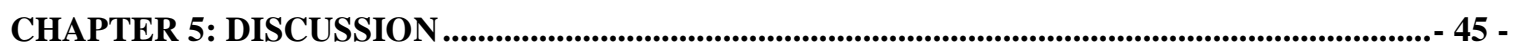

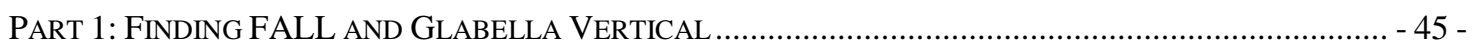

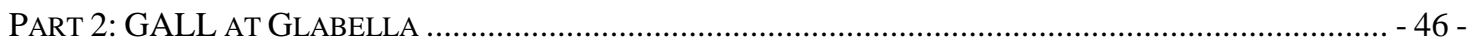

PART 3: NHO IN RELATION TO AP CHIN POSITION …….............................................................. - 49 -

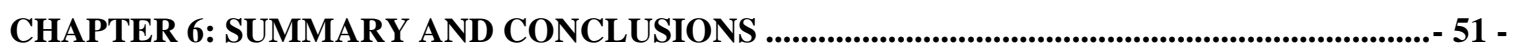

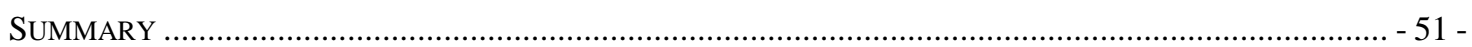

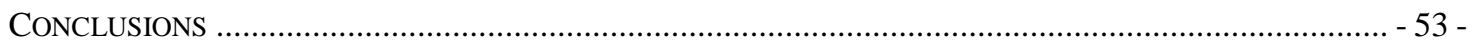

CHAPTER 7: SUGGESTIONS FOR FUTURE RESEARCH .......................................................... - 54 - 
REFERENCES

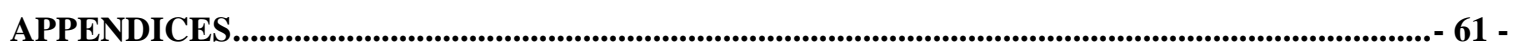

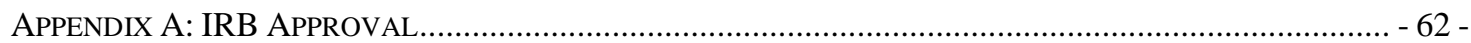




\section{LIST OF TABLES}

Table 1: Six Elements Measurements......................................28

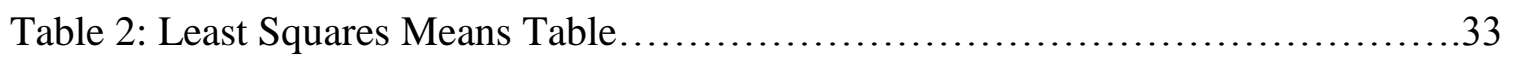

Table 3: Reliability Analysis................................................ 34

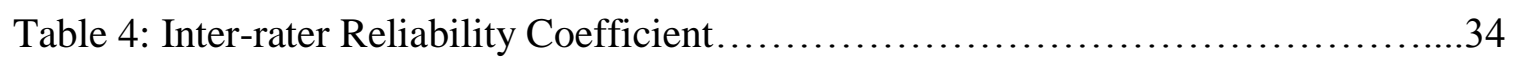

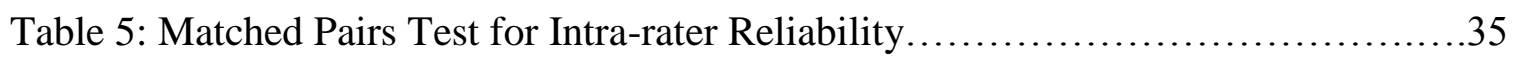

Table 6: Summary Statistics............................................. 36

Table 7: Oneway ANOVA for Mean Angle by Position............................ 38

Table 8: Tukey Kramer Multiple Comparisons Test...............................39

Table 9: Orthodontists vs Non-Orthodontists.................................. 39

Table 10: Males vs Females.................................................. 39 


\section{LIST OF FIGURES}

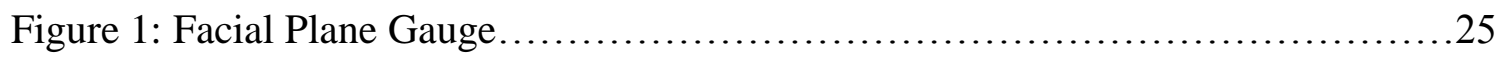

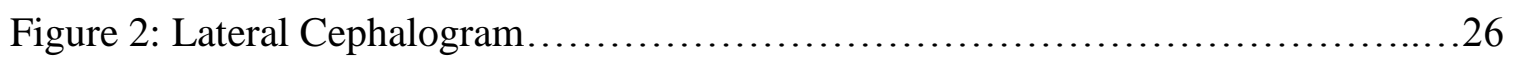

Figure 3: Hard and Soft Tissue Cephalometric Landmarks........................27

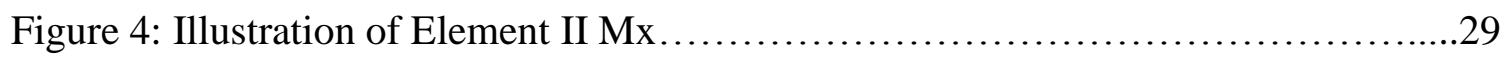

Figure 5: Illustration of Element II Md.................................. 30

Figure 6: Judging NHO in 3 Different Chin Positions: Cl I, II, III.................... 31

Figure 7: The Range of GALL to Glabella...................................43

Figure 8: The Location of GALL in Varying AP Jaw Positions......................45 


\section{LIST OF GRAPHS}

Graph 1: Inter-rater Reliability Coefficient....................................35

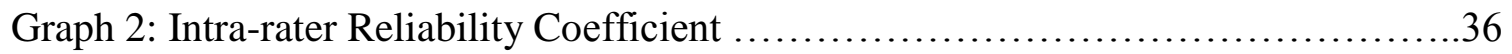

Graph 3: Probability of GALL being Located at Glabella at Different Forehead

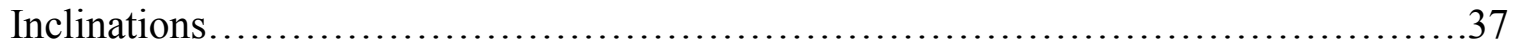

Graph 4: Mean Angle by AP Chin Position........................................... 38 


\section{DEDICATIONS}

To my husband, best friend, love of my life, Travis, for your continual support and love. We have undoubtedly been each other's rock throughout the journey of dental school and orthodontic residency. I am so thankful that I have you by my side. I cannot wait to see what our future holds! I love you!

To my parents, thank you for always believing in me and pushing me to be the best person that I can be. I look up to you for all that you have sacrificed to ensure that I have a wonderful life. I would not have made it through these past years without you. I love you!

To God, thank you for blessing me with this incredible journey in life and for my family, friends, education, and health. I could not be where I am today without my faith in you. 


\section{ACKNOWLEDGEMENTS}

I would like to take this chance to acknowledge not only the individuals who have contributed to my thesis, but also those who have assisted me along the way through my orthodontic residency here at WVU.

Dr. Tremont, thank you for working diligently with me on my thesis project and for being the foundation of our program. I have learned so much from you and am forever grateful. With your guidance, I have gained strength and confidence in my abilities as an orthodontic specialist.

Dr. Martin, thank you for being a member of my thesis committee and for playing an integral role in my education. You have always been such an encouraging person throughout my residency.

Dr. Jurevic, thank you for being a member of my thesis committee and guiding me throughout this self-doubting process. I never would have figured out the IRB without you.

Dr. Erdogen Gunel, thank you for your expertise and time in preparing and interpreting the statistical analyses conducted throughout my project. I could not have done it without you.

Drs. Little, Boyles, Foley, Hazey, Jarrett, Kirsch, McFarland, and Sebbahi, thank you for your dedication to teaching in this program. We all really appreciate the knowledge that you bring from private practice and look up to you.

Karen, Leona, Sandy, Donna, and Amanda, thank you for your assistance and support offered in clinic. I am grateful for having the opportunity to work with you and get to know you.

Sheri, Carol Ann, and Carrie, thank you for always keeping us in line and organized in clinic and classes. I am grateful for having the opportunity to work with you and get to know you.

Nick and Travis, biggest thanks to my amazing classmates/confidants/friends! I am forever grateful to you guys for always being there in good and bad times throughout residency. We have had some awesome times that I will never forget. I look forward to continuing our friendship after residency.

Chad, Doyoung, Alice, Lance, Nicole, and Deepa, Jason, Tim, Martin, Uyen, Marina, and Dobin, thank you all for being supportive, kind, insightful, and fun to be around throughout residency. I cherish having the opportunity to learn with you and consider you all friends. Good luck to each of you in your future endeavors! 


\section{CHAPTER 1: INTRODUCTION}

\section{Background}

The idea of natural head position has been proposed as a reference position for assessing craniofacial morphology since the 1950's by Downs (1956), Bjerin (1957), and Moorrees and Kean (1958). ${ }^{1-3}$ These authors advocated determining a reference plane by the use of a horizontal or vertical line in relation to a natural head position taken when a subject is looking at a distant object at eye level as opposed to intracranial reference lines, such as Frankfort horizontal and sella-nasion line, due to their higher variability. ${ }^{1-4}$ Clinically, NHP can be found by asking a patient to look at his/her own eyes in a small mirror at eye level on the opposite wall. ${ }^{5}$ While NHP stability and reproducibility over both short and long time intervals has been proven by longitudinal studies by Cooke, ${ }^{6}$ its use has not been more widespread. There may be several reasons why NHP has not been utilized routinely such as: confusion over terminology and methodology, lack of reliable reference data, and the fact that positioning someone in NHP takes time.

However, it has been discovered that some patients hold their heads in a flexed or extended position that makes proper diagnosis unlikely with this method. According to previous findings, cervical and head posture are related to different factors such as: stature, ethnicity ${ }^{7,8}$, gender $^{89}$, age, and facial morphology ${ }^{10}$. Bjork and Marcotte demonstrated that head position was more flexed in $\mathrm{Cl}$ III malocclusions and more extended in $\mathrm{Cl}$ II malocclusions. ${ }^{11,12}$ Therefore, Lundstrom et al. ${ }^{4}$ and Lundstrom and Lundstrom ${ }^{13}$ proposed estimated NHP or natural head orientation (NHO) as a better alternative. This position is found when the orthodontist believes the patient's head is located in the correct position. Since NHO is a subjective position found by 
the orthodontist, a significant assumption is that the orthodontist will not be influenced by the patients AP jaw position and/or facial form when making this decision. A purpose of this study was to test this assumption.

Andrews and Andrews ${ }^{14}$ established the Six Elements of Orofacial Harmony, which are characteristics of individuals with balanced faces and optimal occlusion. The Elements serve as a guideline to determine optimal treatment goals for orthodontic treatment. ${ }^{14}$ In this orthodontic philosophy, one must establish a frontal plane in order to orient the lateral cephalogram and photographs for proper diagnosis and treatment planning. An objective of this study is to determine if goal anterior limit line (GALL) is always located at glabella.

The frontal plane is determined by the center of the forehead in relation to the facial axis (FA) point of the maxillary central incisor in millimeters (either a positive number if the FA point is in front or negative number if the FA point is located behind) and is named the forehead anterior limit line (FALL). ${ }^{15}$ This frontal facial plane can be verified with a facial plane (FP) gauge. The FP gauge is a device that you program with your judgment of FALL to touch the FA point of the forehead and the FA point of the maxillary central incisor. When the FALL judgment is correct, the level of the gauge will have the bubble in the center. If the FALL is not correct, the level will be off. At that time, a new FALL is recorded and tried again with the FP gauge. The vertical line of FALL together with forehead inclination is used to determine the socalled GALL. [Fig 1]. An objective of this study is to determine if FALL is a reliable and reproducible judgment and if the FP gauge determines FALL more accurately. Another objective of this study is to determine if Glabella Vertical, a vertical plane formed by a line touching the 
center of glabella in NHO relative to the FA point of the maxillary incisor, is a more reliable and reproducible reference plane.

\section{Statement of the Problem}

In the era of evidence based orthodontics, there is a fundamental need for reliable facial planes to use as landmarks to measure, diagnose, treatment plan, communicate, execute and verify treatment changes. Currently, orthodontists may agree on treatment objectives (proper occlusion, balanced facial form, straight teeth, good jaw relationship, stability, and healthy periodontium) but not on treatment goals. In the Six Elements of Facial Harmony philosophy, referents and landmarks are used for measuring the optimal position of the teeth and jaws. This research will help validate the reliability and reproducibility of current practices in determining facial planes.

\section{Purpose of Study}

The objectives of this study include:

1. Can judgment alone be used as a reproducible method of defining FALL (forehead anterior limit line), a frontal facial plane

2. Can the Facial Plane (FP) Gauge more accurately determine the FALL judgment

3. Can judgment alone be used as a reproducible method of defining Glabella Vertical, a frontal facial plane

4. Can the Facial Plane (FP) Gauge more accurately determine the Glabella Vertical judgment

5. Can judgments of FALL and Glabella Vertical be reproducible over time

6. Can different judges produce the same measurements for FALL and Glabella Vertical 
7. Can Glabella be used as an accurate landmark to locate GALL (goal anterior limit line)

8. Does mandibular AP chin position influence judgment of natural head orientation (NHO)

\section{Null Hypothesis}

1. Judgment alone of FALL is not a reliable method of defining a frontal facial plane

2. The use of the Facial Plane (FP) Gauge is not a more reliable method than judgment alone to define FALL

3. Judgment alone of Glabella Vertical is not a reliable method of defining a frontal facial plane

4. The use of the Facial Plane (FP) Gauge is not a more reliable method than judgment alone to define Glabella Vertical

5. Intra-operator reproducibility of FALL is not consistent

6. Inter-operator reproducibility of FALL is not consistent

7. Intra-operator reproducibility of Glabella Vertical is not consistent

8. Inter-operator reproducibility of Glabella Vertical is not consistent

9. GALL (goal anterior limit line) is not always located at Glabella

10. Mandibular AP chin position does not influence judgment of NHO

\section{Definition of Terms}

Adjusted natural head position - the clinician's judgment of the subject's natural head position when the patient is looking at a distant point at eye level, synonymous to natural head orientation and upright head position 
Anatomical forehead - the exposed skin from the hairline (or where the hairline once was) to glabella

Basal bone - the osseous tissue of the maxilla and mandible that does not include the alveolar process

Centric relation - the maxillomandibular relationship in which the condyles articulate with the thinnest avascular portion of their respective disks with the complex in the most anterior-superior position against the shapes of the articular eminencies

Clinical forehead - the portion of the forehead that is related more with the face than the scalp. For straight foreheads, it is between trichion and glabella. For rounded or angular foreheads, it is between superion and glabella

DALL (dentition's anterior limit line) - a line that parallels the head's frontal plane and passes through the maxillary incisor's facial axis (FA) point

Element I - the position in which a tooth is centered in basal bone with proper inclination for optimal occlusion

Element II - the anteroposterior position of the maxilla and mandible judged as optimal based on the FA point of an Element I maxillary incisor that touches the GALL and is coupled with an Element I mandibular incisor in the Key I position

FA point (tooth) - the point on the facial axis of the clinical crown that is midway between the gingival and occlusal borders

FALL (forehead's anterior limit line) - a line that parallels the head's frontal plane and passes through the FFA point

Forehead's Facial-Axis Point (FFA pt)- a point on the midsagittal plane of the forehead that is midway between the superior and inferior borders of the clinical forehead 
FALL-DALL - the difference between the FALL and DALL measured in millimeters. A negative number will correspond to a DALL that is posterior to the FALL. Zero will indicate that the FALL and DALL coincide. A positive number will correspond to a DALL that is anterior to the FALL

FFA point (forehead facial axis point) - the midpoint of the clinical forehead that is between superion and glabella for round and angular foreheads and is between trichion and glabella for straight foreheads

Forehead Shapes- straight, angular, rounded

GALL (goal anterior limit line) - a line that parallels the head's frontal plane and represents the optimal anterior border for the FA point of an Element I maxillary incisor. This line passes through the FFA point when the forehead inclination is $\pm 7^{\circ}$. For every degree the forehead has an inclination beyond $7^{\circ}$, the GALL passes through a line that is $0.6 \mathrm{~mm}$ anterior to the FFA point; without exceeding the glabella point.

Glabella: a point on the frontal bone that lies above nasion and between the eyebrows; the most inferior border of the clinical forehead

Glabella Vertical: a line that parallels the head's frontal plane in NHO and passes through the glabella point

Key I - Interarch relationships: (1) the mesiobuccal cusp of the maxillary first molar occludes in the mesio-buccal groove of the mandibular first molar; (2) the distal marginal ridge of the maxillary first molar occludes on the mesial marginal ridge of the mandibular first molar; (3) the mesiolingual cusp of the maxillary first molar occludes in the central fossa of the mandibular first molar; (4) the buccal cusps of the maxillary premolars rest in the embrasures of the mandibular premolars; (5) the lingual cusps of the maxillary premolars rest in the fossae of the 
mandibular premolars; (6) the maxillary incisors overlap the mandibular incisors and the midlines of the maxillary and mandibular arch are coincident

Landmark- a point or line that represents anatomy that is actually or hypothetically positioned correct that can be used to measure the quality of the position of anatomy that may or may not be positioned incorrect

Natural Head Orientation - the head orientation of the subject perceived by the clinician, based on general experience, as the natural head position in a standing, relaxed body and head posture, when the subject is looking at a distant point at eye level; same as adjusted natural head position and upright head position

Natural Head Position - a standardized and reproducible orientation of the head when the subject is focusing on a distant point at eye level

Referent- a point or line that represents anatomy whose position is in question

Superion - the point on the angular or round forehead that, in profile, represents the superior boundary of the clinical forehead

The FP Gauge ${ }^{\mathrm{TM}}$ (The Facial-Plane Gauge ${ }^{\mathrm{TM}}$ ) - a measuring device developed by Dr. Timothy Tremont to accurately judge the FALL-DALL measurement

Trichion - the superior border of the anatomical forehead that is rounded or angular in shape

\section{Assumptions}

1. The judges used to make the measurements of FALL and Glabella Vertical have received prior training in making this judgment.

2. The judges used to make the measurements of FALL and Glabella Vertical have received prior training in using the FP Gauge. 
3. The GALL, as determined by the FALL-DALL measurement and forehead inclination, represents a true vertical reference plane.

4. The FALL-DALL measurement was accurately recorded with the patient positioned in NHO.

5. The Glabella Vertical measurement was accurately recorded with the patient positioned in NHO.

6. The lateral cephalometric radiographs are taken with the mandible in centric relation.

7. The lateral cephalometric radiographs have all been traced by one operator.

8. All judges were given instructions on how to place someone in $\mathrm{NHO}$ before the AP chin position study.

\section{Limitations}

- FALL measurement (judged or verified with FP gauge) is relative to NHO. If NHO is incorrect, then FALL judgment may be inaccurate

- Glabella Vertical measurement (judged or verified with FP gauge) is relative to NHO. If NHO is incorrect, then Glabella Vertical judgment may be inaccurate

- Operator error in identification of FALL

- Operator error in identification of Glabella Vertical

- Need for training to make a FALL judgment

- Need for training to make a Glabella Vertical judgment

- Need for training to use Facial Plane Gauge 


\section{Delimitations}

- The three operators determining FALL will have experience judging FALL.

- The three operators determining Glabella Vertical will have experience judging Glabella Vertical.

- The three operators will have experience using the FP Gauge.

- Judgment of FALL and Glabella Vertical will occur at 2 time points: T1-immediate and T2-one month.

- The lateral cephalograms will be obtained from the office of one operator experienced in FALL measurements.

- One individual will be used as a subject for judging NHO with various AP chin positions. 


\section{CHAPTER 2: REVIEW OF THE LITERATURE}

\section{History and Classification of Malocclusion}

Orthodontic problems such as crowding, irregular and protruding teeth date back to the time of the Egyptians. Primitive orthodontic appliances have been found in both Greek and Etruscan materials. ${ }^{16}$ The methods of teeth straightening varied from culture to culture, but the intent was clear - people wanted straight teeth.

After 1850, the first documentation that systematically described orthodontics appeared. Norman Kingsley published Oral Deformities to recommend etiology, diagnosis and treatment planning in orthodontics. ${ }^{17}$ Kingsley also contributed to the profession with the use of an extraoral appliance to correct dental protrusion as well as in the treatment of cleft lip and palate. During this time, the emphasis of orthodontics focused on alignment of the teeth and correction of facial proportions. ${ }^{18}$

One of the most influential figures within the orthodontic profession is Edward H. Angle (1855-1930), who is considered the "Father of Modern Orthodontics". He was actually the first person to declare that orthodontics is a dental specialty. He went on and founded the American Association of Orthodontists (AAO) as well as the first orthodontic school, Angle School of Orthodontia, 1900, and the first orthodontic journal, The American Orthodontist, 1907. ${ }^{18}$

Probably the most notable contribution of Angle is his classification of malocclusions, which was an important step in the development of orthodontics. The Angle classification system consists of four distinct classes: normal Class I occlusion, Class I malocclusion, Class II malocclusion and Class III malocclusion. A Class I malocclusion is defined as a normal molar relationship, whereby the mesiobuccal cusp tip of the maxillary first molars occludes in the mesiobuccal groove of the mandibular first molar, with the presence of tooth 
rotations/malpositions. A Class II malocclusion is defined as a distal position of the mandibular first molar relative to the maxillary first molar. A Class III malocclusion consists of a mesial position of the mandibular first molar relative to the maxillary first molar. Angle advocated treating to a class I occlusion and opposed dental extractions despite negative consequences to facial esthetics. The Angle classification is still used today. ${ }^{18}$

\section{Craniofacial Reference Planes}

Diagnosing and treatment planning in contemporary orthodontics is based on comparing elements of craniofacial morphology to selected reference planes. Ideally, a valid reference plane should have good intra-individual reproducibility, low inter-individual variability, and good reliability. In the past, intracranial and extracranial reference planes have been used. This will provide an overview to the history of each.

A frequently used intra-craniofacial reference plane, which represents the anterior cranial base, is sella-nasion (SN). ${ }^{19}$ It has been found, however, that this plane has very high interindividual variability and 2 to 9 degree average orientation difference from true horizontal. Frankfort horizontal $(\mathrm{FH})$ is another intra-cranial reference plane used to produce an estimation of true horizontal ${ }^{3}$. In 1956 , Downs ${ }^{1}$ discussed the large variation $\left(+9^{\circ}\right.$ to $\left.-7^{\circ}\right)$ in the Frankfort horizontal plane when patients were placed in natural head position.

Several other studies have found considerable angular variation between the horizontal/vertical lines and intra-cranial reference lines such as the sella-nasion line (SD 4.0-4.7 degrees) and Frankfort horizontal (SD 4.6-5.0 degrees). ${ }^{13,20}$ Additional cephalometric reference lines such as basion-nasion and porion-orbitale have also been compared with regard to their 
inclination to the horizontal plane. ${ }^{21}$ They found these angles showed standard deviations between 4.5 and 5.6 degrees. ${ }^{20} 8$

Furthermore, longitudinal growth studies have found that the soft tissue profile does not directly reflect changes in the underlying hard tissue profile ${ }^{22,23}$. In addition, many came to realize that treating patients to dentoskeletal norms does not guarantee an esthetic soft tissue outcome. ${ }^{24}$ Therefore, the use of natural head position in cephalometric treatment planning is advocated due to the large degree of variability of intra-cranial reference planes.

\section{Natural Head Position}

The idea of natural head position (NHP) was originally introduced to orthodontics in the 1950s. ${ }^{1-3}$ These authors used a horizontal or vertical line as a reference plane which they related to the relaxed head posture of standing or sitting subjects. Natural head posture is obtained "when a man is standing and his visual axis is horizontal, he is in the natural position."3. Clinically it is registered by having subjects stand in an upright position and look into their own eyes in a mirror after a series of neck flexion exercises. ${ }^{8}$ A plumb line was used to define the vertical plane on photographs and a horizontal plane at a right angle to the plumb line was transferred from each photograph to a lateral cephalogram through sella to determine true horizontal (HOR).

Other methods of NHP registration include an operator estimated "natural head orientation $^{, 20}$, the use of an inclinometer ${ }^{25,26}$, modified level laser approach ${ }^{27}$, measurement of craniocervical posture $^{28}$, as well as many others. NHP can be recorded photographically ${ }^{21}$ or radiographically. ${ }^{2,29}$ 
NHP as an extra-cranial reference system has been advocated mainly because of its good intra-individual reproducibility to a true vertical plumb line. Lundstrom and Lundstrom ${ }^{21}$ assessed the reproducibility of NHP using pretreatment lateral photographs and cephalometric radiographs. A plumb line identified the true vertical on the photograph, and was then transferred to the lateral cephaolgram. A reproducibility of NHP between the two photographs of $2^{\circ}$ was demonstrated. When compared to the variability of the intra-cranial reference planes, basion-nasion ( $\mathrm{SD}$ of 4.5 -5.0), sella-nasion (SD. 5-5.6), and porion-orbitale (SD of 4.7-5.3) relative to the true horizontal reference line, the use of NHP to establish accurate horizontal and vertical reference lines is supported. ${ }^{21}$

These findings are validated by additional studies demonstrating short-term ${ }^{6,30}$ and longterm reproducibility of NHP. ${ }^{6,30}$ Cooke et al. ${ }^{7}$ found that the method error of NHP after 1 to 2 hours was $1.9^{\circ}$. At the 5 -yr point ${ }^{6}$ and $15 \mathrm{yr}$ point $^{30}$ of a longitudinal study, the method error of NHP was found to be $3.04^{\circ}$ and $2.2^{\circ}$, respectively. Therefore, the variance of NHP is $3.61^{\circ}, 9.24$ ${ }^{\circ}$, and $4.8^{\circ}$ after $1-2$ hours, 5 years and 15 years, respectively. Hence, registrations of NHP are significantly less variable than that of intra-cranial reference planes $\left(25^{\circ}-36^{\circ}\right){ }^{30}$

Further features that authenticate the use of NHP in cephalometric analysis include its representation of a true life appearance and its ease of registration. However, the use of NHP is not widespread for whatever reason. There may be several reasons why NHP has not been utilized routinely such as: confusion over terminology and methodology, lack of reliable reference data, and the fact that positioning someone in NHP takes time. 


\section{Natural Head Orientation}

Several factors of a physiological, psychological as well as of a pathological nature are involved in the concept described as registered natural head posture. ${ }^{31}$ The orientation of the bony labyrinth of the inner ear, muscular posture, individual awareness of deviations in facial appearance such as an attempt to mask chin retrusion, and nasal obstruction may affect the way a person holds their head in an "upright" head position. ${ }^{32}$ Therefore, Lundstrom introduced a new concept, defined as the head position adjusted from the registered NHP to a position judged to be the natural head orientation by the orthodontist (NHO). ${ }^{13}$ This position (NHO) is defined as the head position evaluated as "natural" by observers. Studies have found that the NHO related horizontal line through sella to be a very reliable reference plane for clinical cephalometric analysis compared to NHP. ${ }^{20,21}$

\section{Relationship of Natural Head Position to Craniofacial Morphology}

According to previous studies, cervical and head posture are related to different factors such as ethnicity ${ }^{7,33}$, gender ${ }^{33}$, age and facial morphology (mandibular divergence). ${ }^{10}$ In addition, functional factors that influence head posture include nasorespiratory function ${ }^{9}$, temporomandibular dysfunction ${ }^{34}$, and bruxism. ${ }^{35}$ Bjork and Marcotte demonstrated that head position was more extended in Class II malocclusion whereas a more flexed head posture was seen in individuals with Class III malocclusion. ${ }^{11,12}$ A more extended head posture was also found in children with Class II malocclusions in studies by Gonzalez and Manns ${ }^{36}$ and Festa et al. ${ }^{37}$

Natural head orientation has been recommended over natural head position as a preferred reference position for assessing facial morphology in orthodontic and orthognathic treatment 
planning due to the above mentioned factors. However, a significant assumption made is that the orthodontist who judges NHO is not influenced by a patient's facial form. Some studies have found that observers tend to rotate the face upward and forward in cases with retruded chin positions and adjust the head downward and back in protruded chin positions. ${ }^{31,38,39}$ Chin position, was considered an important factor affecting NHO so that true skeletal relationships were underestimated. ${ }^{38}$

Another study found that natural head orientation could be created with great reproducibility through orientation of profile images in different chin positions. ${ }^{40}$ They found that although NHO may be influenced by Class II and Class III patients, this influence is not clinically significant. ${ }^{40}$

\section{Determining Natural Head Orientation 3-Dimensionally}

In contemporary orthodontics, there is an increased interest in 3-dimensional craniofacial analysis. Although natural head orientation has been proven to be reproducible and reliable in the sagittal plane, a determination of its reproducibility in the coronal and axial plane is essential for 3-dimensional imaging.

A low-cost, 3-dimensional (3D) laser scanner can be used as a soft tissue scanner; it is a valuable tool for its ease of application and creation of 3D images. Studies have shown that the Minolta 900 scanner is accurate to $0.56+/-0.25 \mathrm{~mm}$, and the error in computerized registration of

left and right scans is $0.13+/-0.18 \mathrm{~mm} .{ }^{41}$ Also the data captured on children has been shown to be reliable and able to be captured at different time points to assess growth as a result of facial change and treatment. ${ }^{42}$ 
3- dimensional cone-beam computer tomography (CBCT) offers diagnostic advantages over conventional 2-dimensional imaging. However, there are difficulties in orienting the volume in existing 3D imaging software programs due to the absence of external references during the $\mathrm{CBCT}$ acquisition process. Cevidanes et al ${ }^{43}$ presented a way of positioning the $\mathrm{CBCT}$ volume in the software with a simulated natural head position. Another study found that NHP is reproducible in the coronal, axial, and sagittal planes of space over time with a 3D stereophotographic system linked with a CBCT image. ${ }^{44}$ Xia et al ${ }^{45}$ developed a NHP recording device assembly that can accurately record NHP in three dimensions and precisely transfer it to a 3D model.

\section{Six Elements}

The Andrews ${ }^{\circledR}$ Six Elements Orthodontic Philosophy ${ }^{\mathrm{TM}}{ }^{15}$ is an approach to overcome the shortcomings of traditional cephalometric analyses by completing an analysis unique to each individual. The Six Elements of Orofacial Harmony ${ }^{\mathrm{TM}}$ is defined by Lawrence F. Andrews are optimal treatment goals for teeth, arches, and jaws. ${ }^{15}$ The six characteristics include: Element I: dental arch shape and length; Element II: anteroposterior jaw positions; Element III: buccolingual jaw positions; Element IV: supero-inferior jaw positions; Element V: pogonion prominence and Element VI: dental occlusion. Dr. Andrews established a set of goals, objectives, landmarks, and referents to define the optimality of each element. The Six Elements ${ }^{\mathrm{TM}}$ allows for a comprehensive classification system representing both the position of the teeth and the jaws. This classification system is different from other philosophies in that cephalometric norms are not used to diagnose and treatment plan a case.

Exclusive to the Six Elements Philosophy is the evaluation of the lateral smiling profile. Andrews sees it as a paradigm shift from the traditional soft tissue profile evaluation. He noted 
that a relationship exists between the forehead inclination and prominence and the AP position of the maxillary central incisor in patients with harmonious profiles. This relationship created can be used to create a frontal plane, the Goal Anterior Limit Line (GALL), to judge the optimal AP position of the jaws. One study confirmed that $91 \%$ of the individuals with a good to excellent facial profile fall within the GALL and FA point of the forehead. ${ }^{46}$ Schlosser et al. ${ }^{47}$ rated facial attractiveness using the position of the maxillary central incisors with reference to the forehead. Both studies support the use of the forehead to determine the AP position of the maxilla and mandible, which is essential to the Six Elements classification system.

Below is a summary of each Element. For a comprehensive guide to the Six Elements of Orofacial Harmony, please refer to the Andrews ${ }^{\circledR}$ Foundation course syllabus. ${ }^{15}$

\section{Element I:}

Element I describes the shape and length of the dental arches. An arch is optimal when teeth are positioned in the correct inclination, roots are centered in basal bone, and the curve of spee is between $0-2.5 \mathrm{~mm}$. The dental arch shape of the mandible is determined by evaluating the bucco-lingual distance between each tooth's facial-axis (FA) point and the WALA Ridge. The WALA ridge is the ridge of soft tissue directly superior to the mucogingival junction and is suggested to approximate the center of rotation of each tooth. The buccolingual distance between the FA point and the WALA ridge progressively decreases from posterior to anterior. The distance averages $2.2 \mathrm{~mm}$ at the second molar and $0.1 \mathrm{~mm}$ at the central incisor. The maxillary arch form is then established based on the mandibular arch form.

The lateral cephalometric radiograph is used to determine Element I incisors. The occlusal plane is first identified; the Andrews template is then utilized to determine the proper inclination of the maxillary and mandibular central incisors with the roots centered in basal bone. 
The template incisor inclination relative to the occlusal plane ensures an optimal inclination $\left(7^{\circ}\right.$ for the maxillary incisor and $-1^{\circ}$ for the mandibular incisor) relative to the dental arch's perimeter line.

An evaluation of Element I will require an analysis of the core discrepancy (crowding). Calculations must be made to determine the effects that uprighting the molars, leveling the curve of Spee, expanding the maxilla and proclining/retroclining the incisors will create on the core discrepancy. These are used to determine the interim core discrepancy (ICD). A positive ICD indicates spacing whereas a negative ICD indicates crowding. The ICD is then utilized for treatment decisions such as the need for proclination, interproximal reduction, or extractions.

\section{Element II:}

The objective of Element II is an evaluation of the anteroposterior position of the jaws. The Goal Anterior Limit Line (GALL) represents the frontal plane of the head, and is identified based on an evaluation of the forehead shape and inclination. Three classifications of forehead shapes are determined; straight, angular, and round. The forehead points, trichion, superion, glabella and the foreheads facial axis point, are identified for each patient based on forehead shape. The distance between the forehead anterior limit line (FALL) and the dentition's anterior limit line (DALL) is evaluated clinically with the patient in an upright head position and recorded. The DALL is a line passing through the FA point of the maxillary incisor that parallels the frontal plane of the head. The FALL is a line passing through the FFA point of the forehead that parallels the frontal plane of the head. The angular measurement determined by the forehead inclination (superion and/or trichion to glabella) relative to the FALL is recorded. The FALL is equivalent to the GALL with a forehead inclination between $-7^{\circ}$ to $+7^{\circ}$. For every 
degree beyond the range $-7^{\circ}$ to $+7^{\circ}$, the GALL lies $0.6 \mathrm{~mm}$ anterior to the FALL, without exceeding glabella.

An optimal Element II maxilla requires the FA point of the maxillary central incisor to lie on the GALL. The maxilla can be classified as black (retrognathic) or red (prognathic) by measuring the distance from the maxillary incisor FA point to the GALL. An optimal Element II mandible is determined relative to an optimal Element II maxilla, with the teeth in an Element I position and a Key I dental relationship. The mandible can be classified as black (retrognathic) or red (prognathic) by measuring the distance from the optimal Element I and Element II maxillary incisor to the Element I mandibular incisor.

The AP jaw classification represents the jaw discrepancy relative to optimally positioned incisors. This is different from traditional cephalometric assessments which assess the jaw positions based on linear measurements or angles of specific jaw landmarks; such as the ANB.

\section{Element III:}

Element III is an evaluation of the transverse dimension of the maxilla relative to the mandible. The mandible represents the basis from which to measure the optimal bucco-lingual position of the maxilla. The cusp-cusp and fossa-fossa distances are measured within the maxilla and mandible with the teeth in an Element I position to determine if a discrepancy exists. If there is a discrepancy, the maxilla can be orthopedically or surgically expanded to match the mandibular width. The distance between FA point of the mandibular posterior teeth and WALA ridge, is used to determine the Element I tooth position and if uprighting is needed for mandibular posterior teeth inclined to the lingual. The amount of uprighting should be incorporated into the fossa-fossa transverse mandibular measurements. 


\section{Element IV:}

The optimal jaw heights in the supero-inferior dimension are evaluated with Element IV. Jaw heights are optimal when: the teeth are in centric relation, the supero-inferior positions of the Element I maxillary central incisors are in harmony with the inferior border of the upper lip in repose, the occlusal plane inclination is between +2 and $+10^{\circ}$ relative to a patient in adjusted upright head position, and the lower anterior and posterior face heights are within $10 \mathrm{~mm}$ of the middle anterior face height.

\section{Element V:}

Element $\mathrm{V}$ is an evaluation of hard-tissue AP pogonion prominence. Element $\mathrm{V}$ is defined as optimal based on a pogonion prominence that lies on a line $90^{\circ}$ to the occlusal plane that passes through the FA point of the Element I mandibular incisor. The amount of deviation anterior or posterior to this line is recorded as positive or negative, respectively.

\section{Element VI:}

The Six Keys to Optimal Occlusion is the basis for Element VI. When all six keys are present, Element VI is considered optimal. Lawrence F. Andrews published The Six Keys to Normal Occlusion ${ }^{14}$ which he later modified the name to the Six Keys to Optimal Occlusion. Andrews studied 120 dental casts with optimal occlusions to determine if there were any universal characteristics that exist. Within these casts the constancy of features were found: Key; I) correct interarch relationships; II) correct crown angulation; III) correct crown inclination; IV) absence of rotations; V) tight contacts; and VI) a flat curve of Spee. These characteristics which define an optimal occlusion are widely used and accepted. 
Dr. Andrews's study of optimal dental casts established the basis from which he developed the fully programmed Straight Wire Orthodontic Appliance. This discovery revolutionized contemporary orthodontic treatment.

\section{CHAPTER 3: MATERIALS AND METHODS}

\section{Sample Description}

\section{Inclusion Criteria}

- Subjects 18 years of age or greater in the permanent dentition

- Three operators judging FALL will have prior training with the FP Gauge

- Three operators judging Glabella Vertical will have prior training

- Judges of natural head orientation will have dental backgrounds

\section{Exclusion Criteria}

- Presence of any craniofacial anomalies; eg: Cleft lip and palate.

- Patients currently in orthodontic treatment

- Subjects under 18 years of age

\section{Research Design}

\section{Part 1: Finding FALL and Glabella Vertical}

Prior to initiating this study, IRB approval was obtained from West Virginia University. The experimental group will consisted of 24 randomly chosen subjects that were not currently 
in orthodontic treatment. Three operators that have training with determining a FALL judgment and the use of the FP Gauge participated in this study. First, a judgment (F) of FALL was obtained by orienting a patient in NHO. Next a corrected judgment (FC) was obtained by making a judgment of FALL and verifying it with the Facial Plane (FP) Gauge. Next a judgement of Glabella Vertical (G) was obtained by orienting a patient in NHO. Then a corrected judgement of Glabella Vertical (GC) was made with the Facial Plane Gauge. Both techniques were completed at 2 different time points: 1) immediately 2) one month later. Correlations were made between judgment and corrected judgment, and reliability between intra- and inter-operators. See figure 1 . 


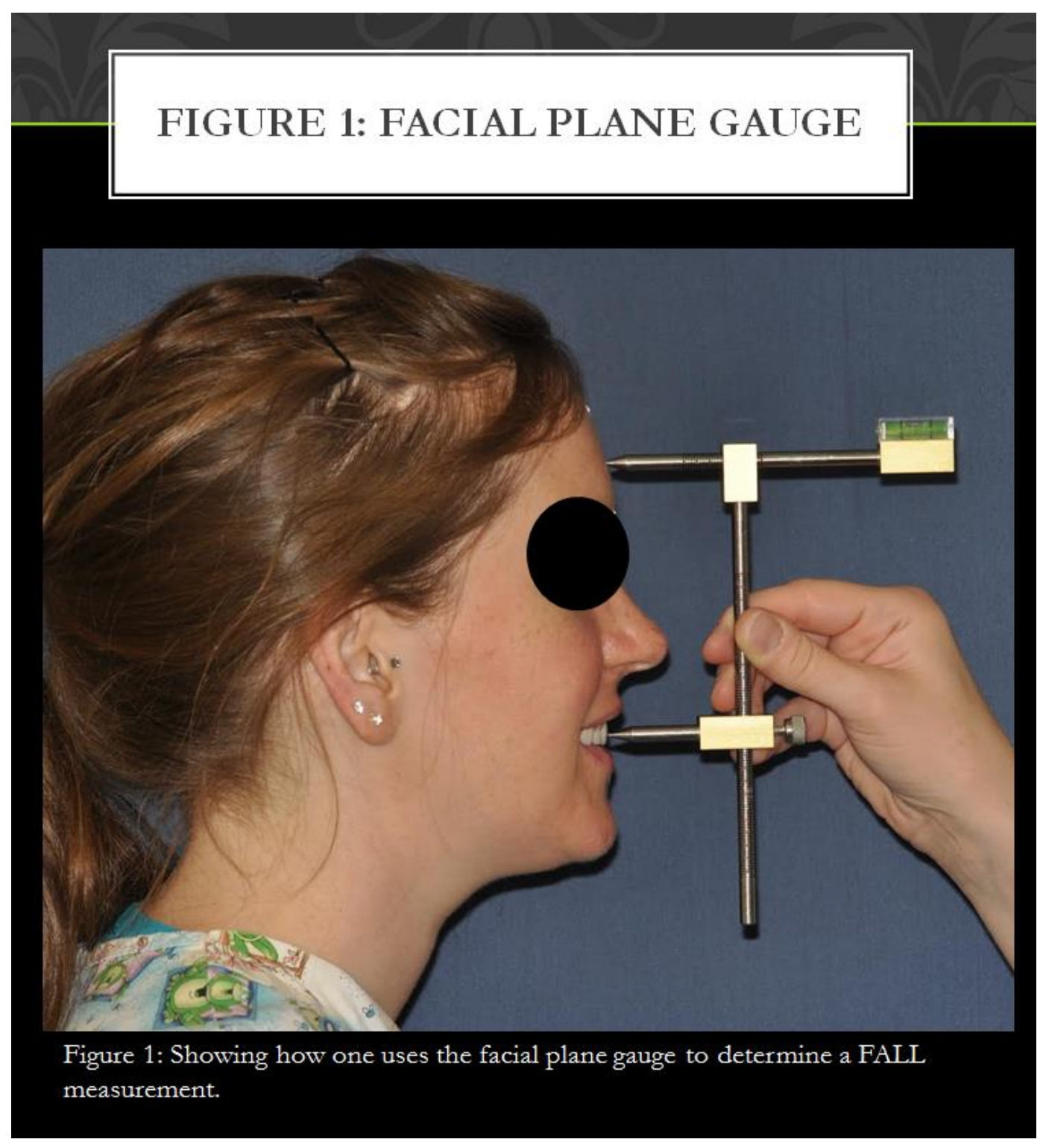

\section{Part2: GALL at Glabella}

105 randomly traced lateral cephalograms with the Six Elements Analysis were studied and the GALL was measured (in $\mathrm{mm}$ ) from Glabella. Correlations were investigated between maxillary and mandibular AP relationships, forehead shape, forehead inclination, and the location of GALL. These records were obtained from the private practice of Dr. Timothy Tremont in White Oaks, PA. See figure 2. 


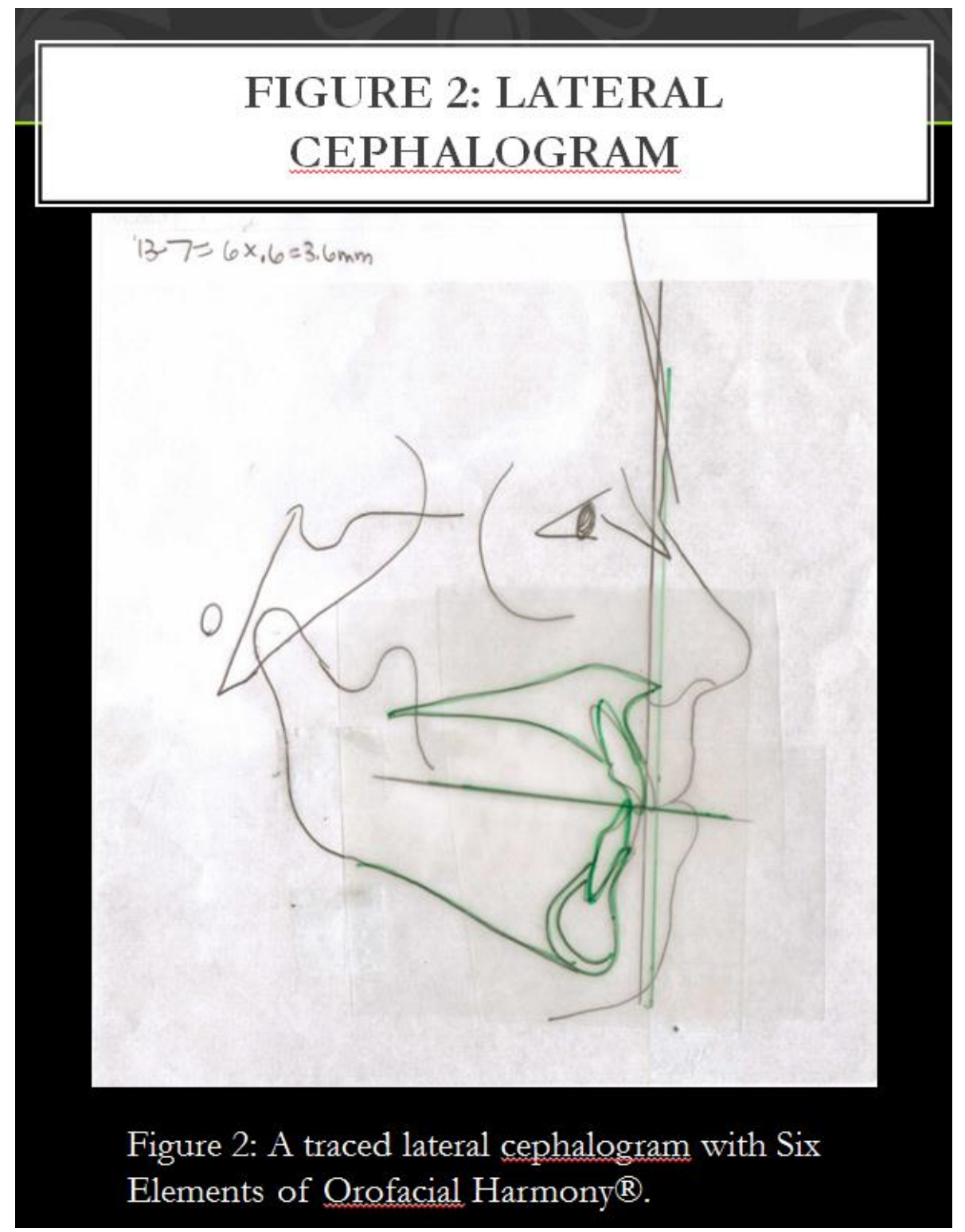

\section{Cephalometric Analysis}

\section{Landmark Identification:}

The lateral cephalometric radiograph was used for analysis of the cephalometric variables.

Landmark identification (Fig. 3), tracings and measurements were completed by a single investigator. 


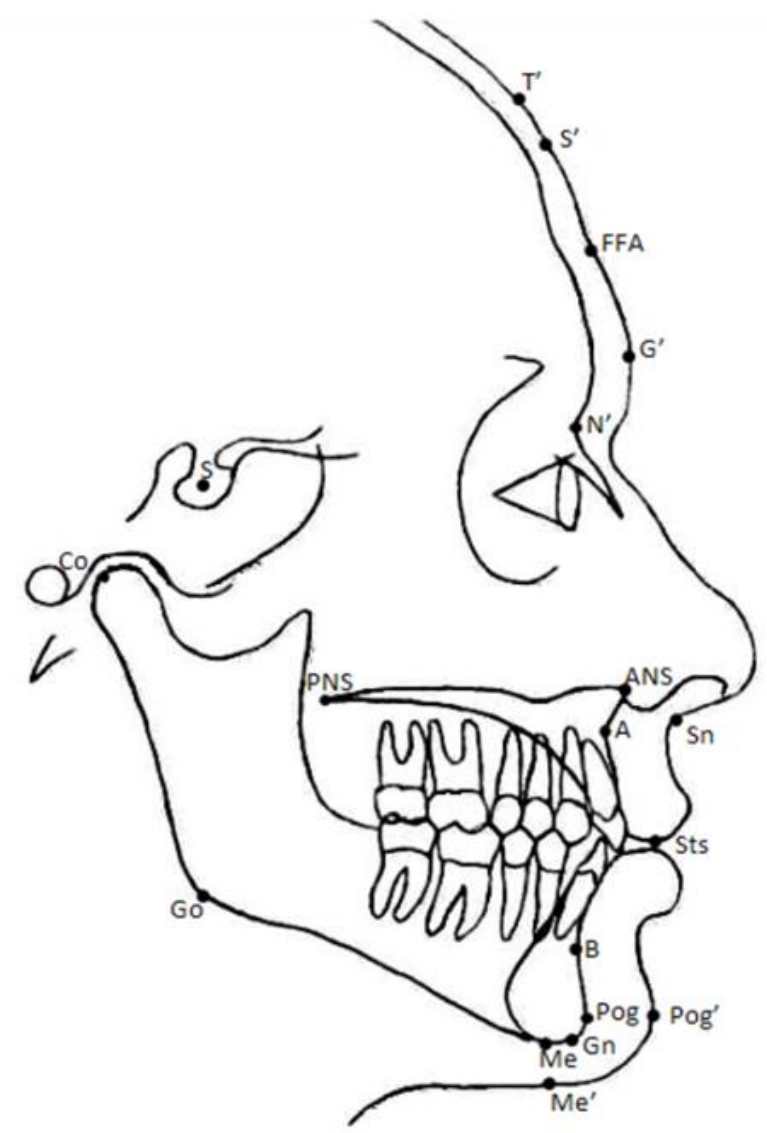

Fig. 3: Hard and Soft Tissue Cephalometric Landmarks

\section{Six Elements Measurements:}

The cephalometric analysis included a measurement of several of Andrew's Six Elements. For an overview of these measurements please refer to table 1 below. 
Table 1: Six Elements Measurements

Variable

Definition

II Mx The antero-posterior position of the maxillary central incisor relative to the GALL; measured in millimeters from the GALL to the maxillary central incisor FA point. A negative value indicates that the FA point is posterior to the GALL. A positive value indicates that the FA point is anterior to the GALL.

II Md The antero-posterior position of the mandibular central incisor measured relative to an optimal Element II maxillary central incisor. A negative number indicates the measurement in millimeters of overjet. A positive number indicates the measurement in millimeters of anterior crossbite.

IV Mx Ant The vertical position of the anterior maxilla. Measured as the vertical distance of the FA point of the Element I maxillary central incisor relative to Sts. A positive number indicates that the FA point is more inferior to Sts. A negative number indicates that the FA point is more superior to Sts.

IV Md Ant The vertical position of the anterior mandible. Measured as the vertical distance from the FA point of the Element I mandibular central incisor to Me.

V Pogonion Prominence. The distance between Pog to a line formed tangent to the FA pt of an Element I mandibular central incisor and perpendicular to the occlusal plane. 
Element II was recorded by utilizing the (C) 1996 Lawrence F. Andrews Foundation tracing template, superimposed on the occlusal plane to draw a hypothetically positioned Element I maxillary and mandibular incisor. The Element II position of the maxilla was measured as a linear distance from the FA point of the Element I maxillary to the GALL. A negative measurement was recorded with the FA point posterior to the GALL. A positive measurement was recorded with the FA point anterior to the GALL. (Fig. 4)
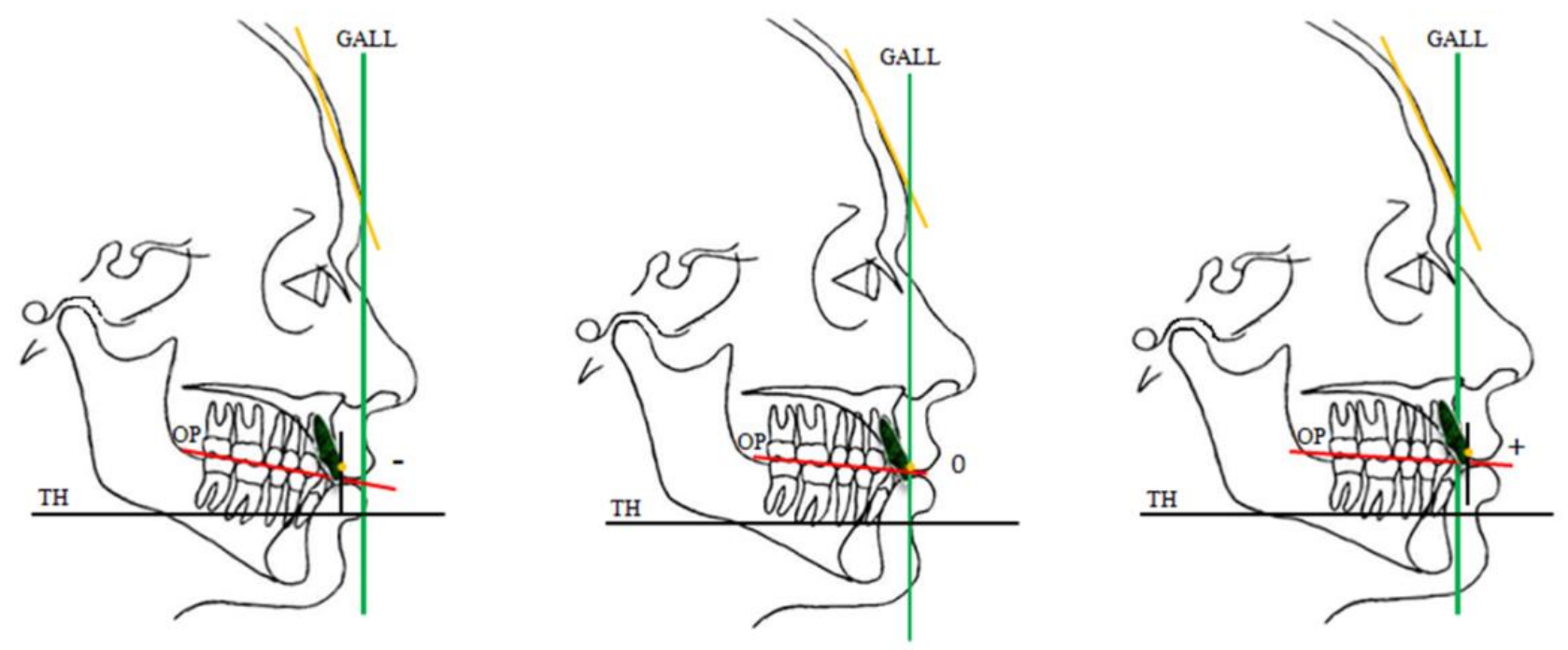

Fig. 4: Illustration of Element II Mx

The Element II position of the mandible was recorded as the AP distance of the mandibular central incisor measured relative to an optimal Element II maxillary central incisor. A negative 
number indicates the measurement in millimeters of overjet. A positive number indicates the measurement in millimeters of anterior crossbite. (Fig. 5)
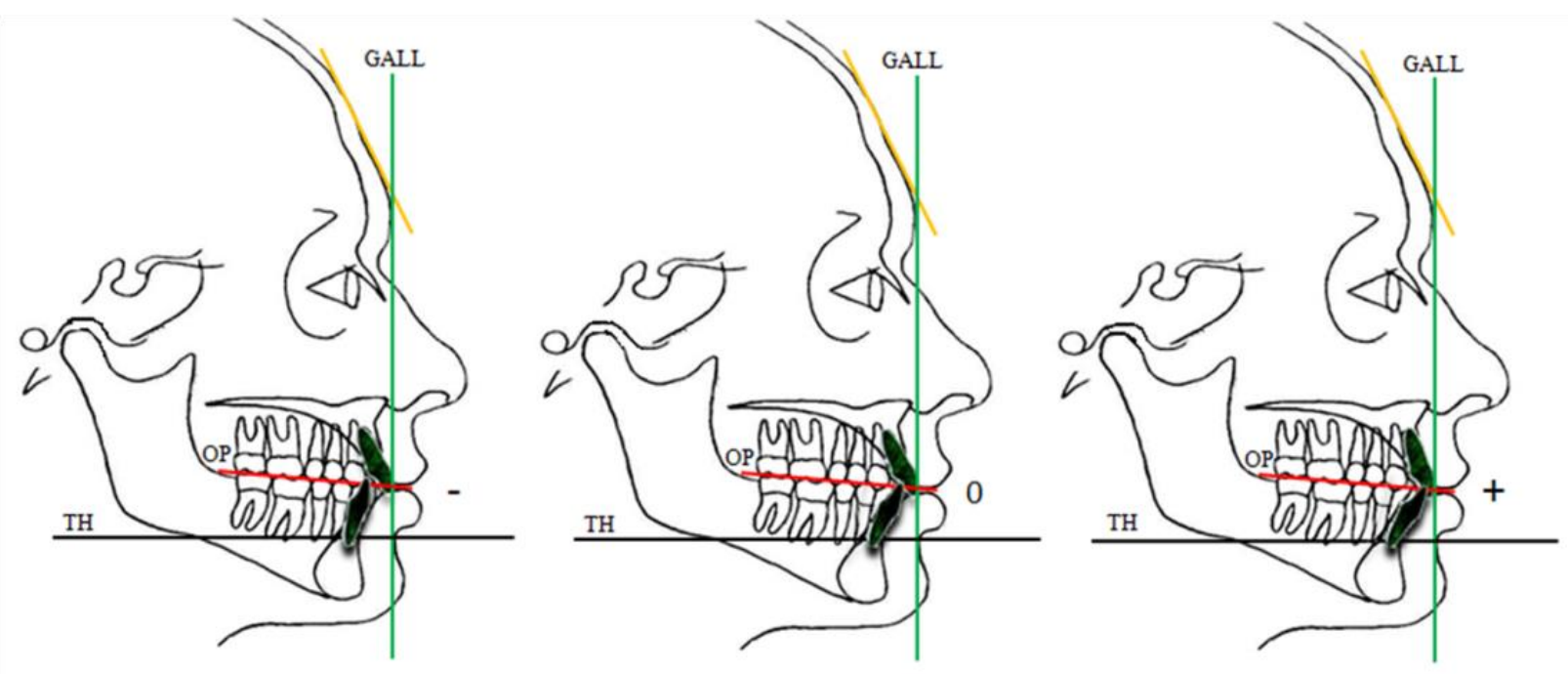

Fig. 5: Illustration of Element II Md

\section{Linear Measurements:}

The linear cephalometric measurements were measured utilizing the (C) 1996 Lawrence F. Andrews Foundation protractor, and recorded to the nearest $0.5^{\circ}$. These measurements included 1) GALL to Glabella and 2) Element II Mx and Md Incisor positions.

\section{Angular measurements:}

The angular measurements were measured utilizing the (C) 1996 Lawrence F. Andrews Foundation protractor, and recorded to the nearest degree. These measurements included: forehead inclination. 


\section{Part 3: AP Jaw Position}

A skeletal and dental class II subject with normal maxilla and retrusive mandible was selected. Bite registrations were made by sliding the $\mathrm{Cl}$ II patient's jaw forward into a $\mathrm{Cl}$ I occlusion and also by sliding the subject's jaw forward into a $\mathrm{Cl}$ III occlusion. A judgment of NHO was determined by 26 operators for all three profile schemes (I, II, III). The NHO was measured as an angle between a horizontal plane projected from a laser and a line connecting two marker points on the forehead and nose.

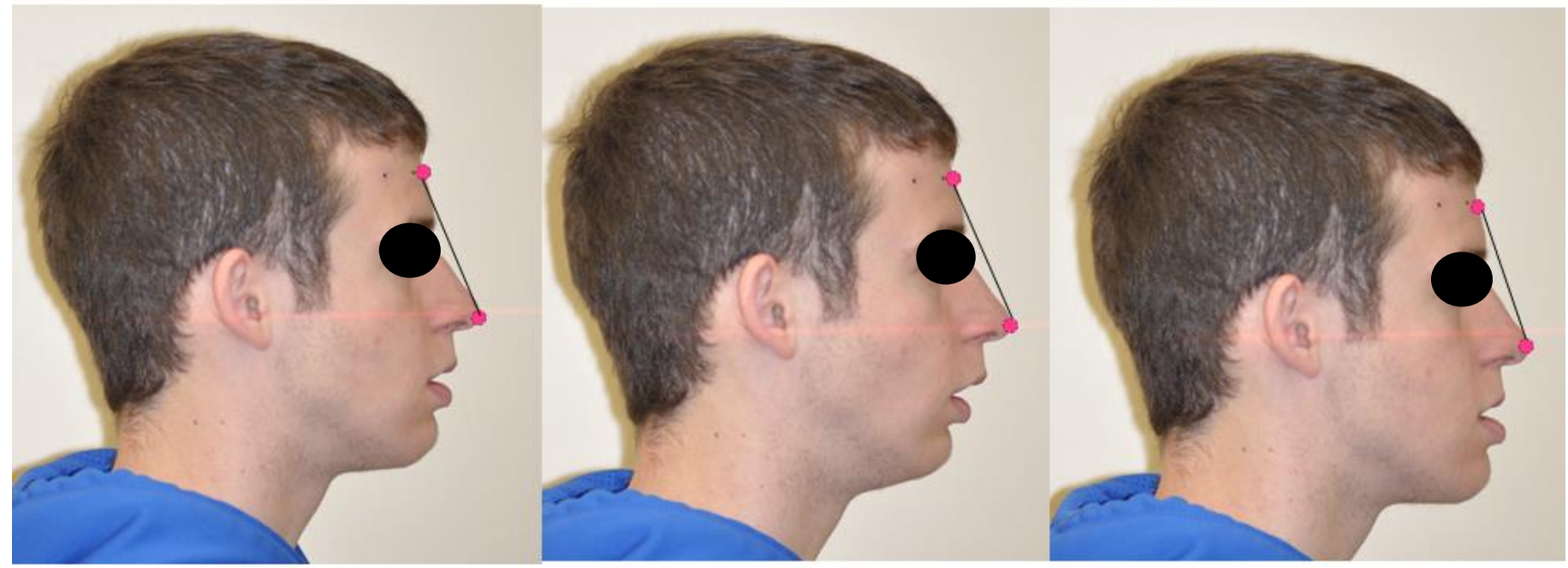

Figure 6: Judging NHO in 3 different chin positions: Class I, Class II, and Class III. 


\section{Statistical Analysis}

The statistical analysis was carried about by the statistician (E.G.) utilizing the JMP version 10 SAS Software. For part 1, An Analysis of Variance (ANOVA) was used for comparison of the measurements for variables $\mathrm{F}, \mathrm{FC}, \mathrm{G}$, and $\mathrm{GC}$ for the 3 raters. The inter-rater reliability coefficient was then calculated. Finally a matched pairs test was calculated to determine intra-rater reliability between $\mathrm{T} 1$ and $\mathrm{T} 2$ time points. The significance level was set at $\mathrm{p}<.05$.

For part 2, a t-test was used to determine if GALL is always located at Glabella. The significance level was set at $\mathrm{p}<.05$. Then a logistic regression analysis was performed to see if there were any correlations with the location of GALL to Glabella and forehead shape, skeletal pattern, gender, age, FALL/DALL, and forehead inclination.

For part 3, An ANOVA and a Tukey Kramer multiple comparison analysis was used for comparison of angle means at Class I, II, and III. Also an ANOVA was used to determine if there was significance in terms of operators (orthodontists vs non-orthodontists) or gender (male vs female) for Class I, II, and III. The significance level was set at $\mathrm{p}<.05$. 


\section{CHAPTER 4: RESULTS}

\section{Part 1: Finding FALL and Glabella Vertical}

\section{Table 2: Least Squares Means Table}

\begin{tabular}{llrrr} 
Variable & Time & Rater & $\begin{array}{r}\text { Std. } \\
\text { Error }\end{array}$ & Mean \\
\hline F & T1 & 1 & 0.34 & 1.695 \\
\hline F & T1 & 2 & 0.34 & 2.478 \\
\hline F & T1 & 3 & 0.34 & 0.783 \\
\hline F & T2 & 1 & 0.26 & 1.739 \\
\hline F & T2 & 2 & 0.26 & 2.957 \\
\hline F & T2 & 3 & 0.26 & 0.957 \\
\hline FC & T1 & 1 & 0.3 & 2.043 \\
\hline FC & T1 & 2 & 0.3 & 2.869 \\
FC & T1 & 3 & 0.3 & 0.957 \\
\hline FC & T2 & 1 & 0.28 & 1.739 \\
\hline FC & T2 & 2 & 0.28 & 3.217 \\
\hline FC & T2 & 3 & 0.28 & 0.869 \\
\hline G & T1 & 1 & 0.24 & -1.348 \\
\hline G & T1 & 2 & 0.24 & -1.522 \\
\hline G & T1 & 3 & 0.24 & -2.304 \\
\hline G & T2 & 1 & 0.25 & -1.217 \\
\hline G & T2 & 2 & 0.25 & -0.348 \\
\hline G & T2 & 3 & 0.25 & -1.609 \\
\hline GC & T1 & 3 & 0.25 & -1.391 \\
\hline GC & T1 & 1 & 0.25 & -1.391 \\
\hline GC & T1 & 2 & 0.25 & -2.304 \\
\hline GC & T2 & 3 & 0.28 & -1.304 \\
\hline GC & T2 & 0.28 & -0.304 \\
\hline GC & 25 & -1.783 \\
\hline & & & & \\
\hline
\end{tabular}

The three raters differ from one another with respect to mean levels of all measurements. See table 2 . 


\begin{tabular}{llr}
\multicolumn{2}{l}{ Table 3: Reliability Analysis } \\
Variable & Time Point & P-value \\
\hline F & T1 & 0.004 \\
F & T2 & 0.0001 \\
\hline FC & T1 & 0.0002 \\
\hline FC & T2 & 0.0001 \\
\hline G & T1 & 0.01 \\
\hline G & T2 & 0.003 \\
\hline GC & T1 & 0.01 \\
\hline GC & T2 & 0.002 \\
\hline
\end{tabular}

The ANOVA showed that the 3 raters have statistically significant different mean levels of measurements for all variables (F, FC, G, GC). In all cases the hypothesis of equal rater effects is rejected.See Table 3 .

\begin{tabular}{llr} 
Table 4: Interrater Reliability Coefficient \\
Variable & Time & Reliability Coefficient \\
\hline F & T1 & 0.67 \\
F & T2 & 0.73 \\
FC & T1 & 0.73 \\
FC & T2 & 0.72 \\
G & T1 & 0.8 \\
G & T2 & 0.76 \\
GC & T1 & 0.8 \\
GC & T2 & 0.73 \\
\hline
\end{tabular}




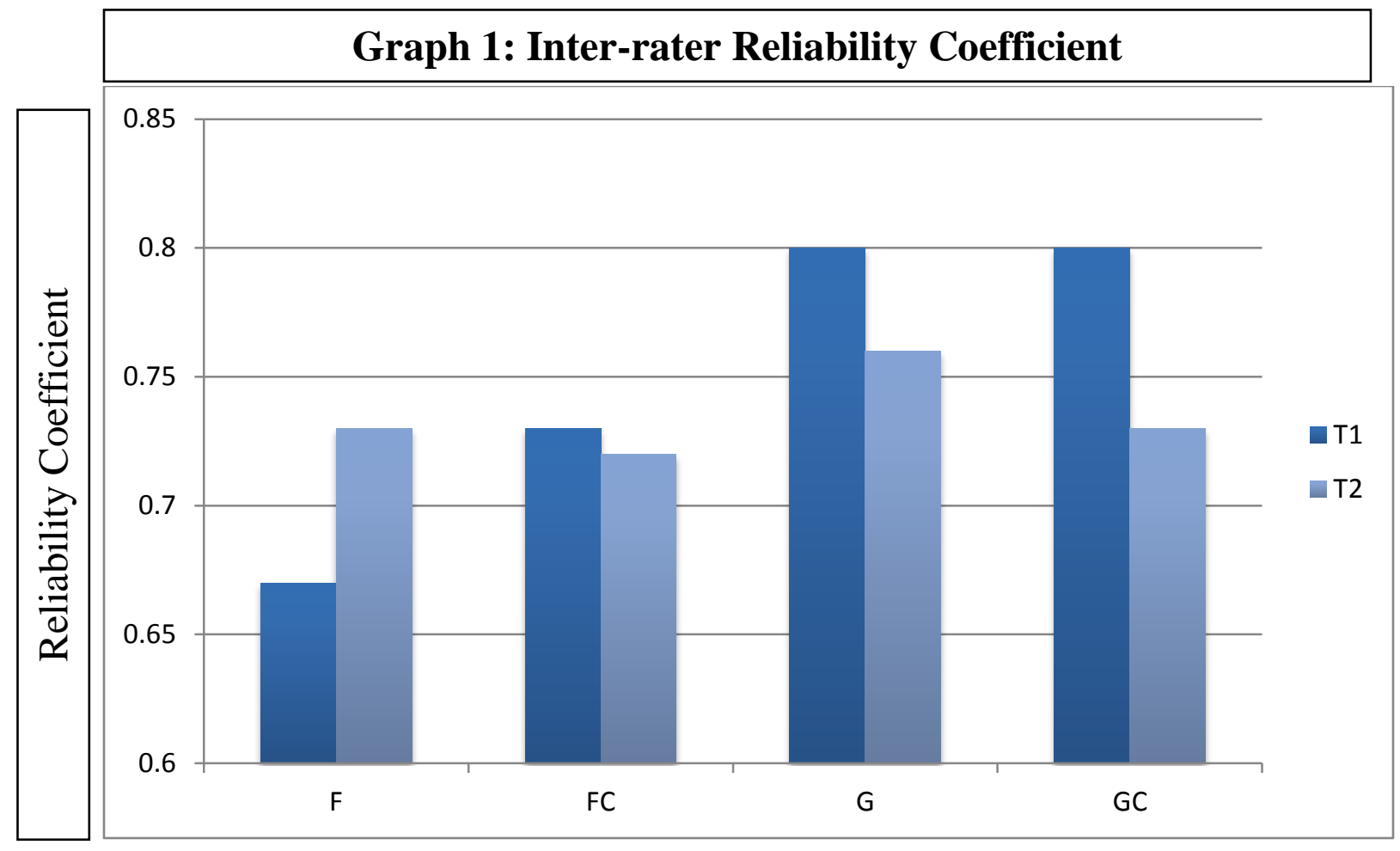

The inter-rater reliability coefficient was moderate to good among the 3 raters. See table 4 and graph 1.

Table 5: Matched Pairs Test for Intra-rater Reliability

\begin{tabular}{lrc} 
Variable & Rater & Reliability Coefficient \\
F & 1 & 0.86 \\
FC & 1 & 0.88 \\
G & 1 & 0.93 \\
GC & 1 & 0.93 \\
F & 2 & 0.83 \\
FC & 2 & 0.85 \\
G & 2 & 0.84 \\
GC & 2 & 0.85 \\
F & 3 & 0.76 \\
FC & 3 & 0.8 \\
G & 3 & 0.89 \\
GC & 3 & 0.88 \\
\hline
\end{tabular}




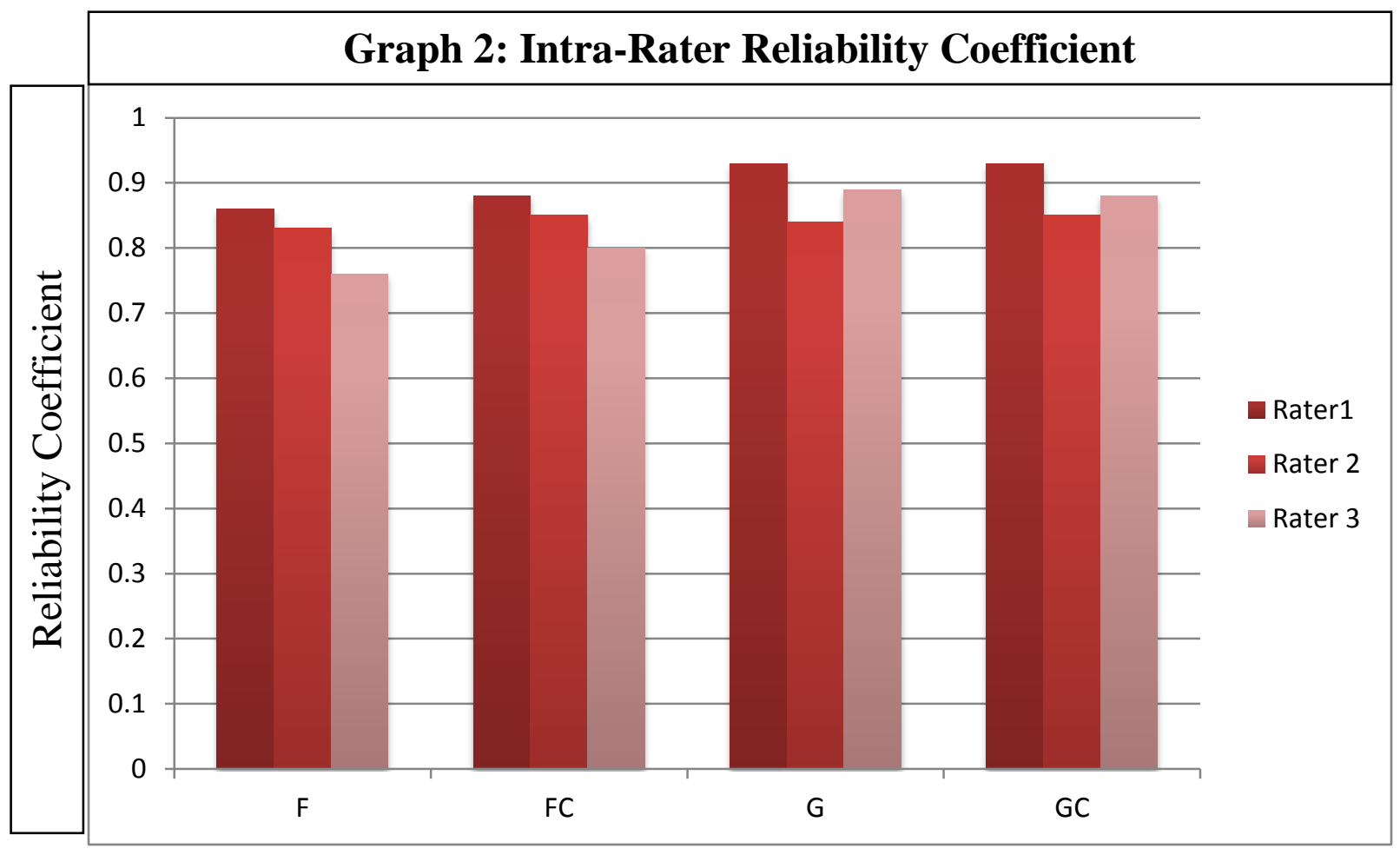

The intra-rater reliability coefficient was high in regards to measurements from time point 1 (T1) to time point 2 (T2). See table 5 and graph 2.

\section{Part 2: GALL at Glabella}

Table 6: Summary Statistics

Distance from GALL to glabella $(\mathrm{N}=105)$

Mean

$-0.224$

Std. deviation

0.485

Std. error mean

0.047

Prob. of t test $<.0001$

The t-test showed statistical significance in regards to the location of GALL = Glabella (P-value $<0.001)$. See table 6. 


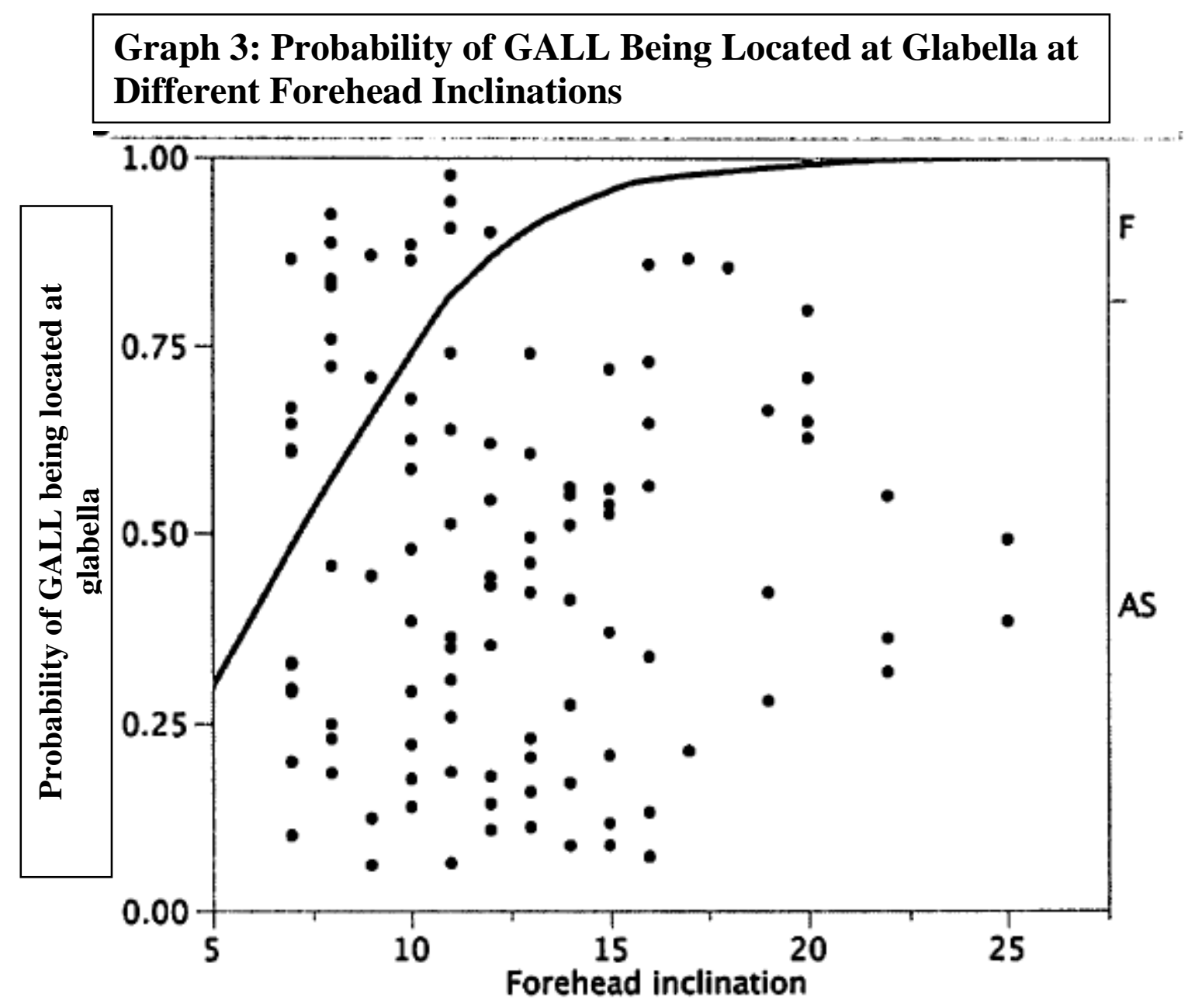

The logistic regression analysis showed that forehead inclination is the only variable that has a correlation with the location of GALL to Glabella. As the forehead inclination increases, the probability that GALL is located at Glabella is increased. For instance, with a $7^{\circ}$ forehead inclination, the probability that GALL is located at glabella is $50 \%$. With a $15^{\circ}$ forehead inclination, the probability that GALL is located at glabella is $95 \%$. See graph 3. 


\section{Part 3: AP Jaw Position}

\begin{tabular}{lccr} 
Table7: Oneway ANOVA for Mean Angle by Position & \\
Variable & Mean & Std. Error & P-value \\
\hline Class I & 71.904 & 0.356 & 0.0133 \\
Class II & 71.231 & 0.356 & 0.0133 \\
Class III & 72.75 & 0.356 & 0.0133 \\
\hline
\end{tabular}

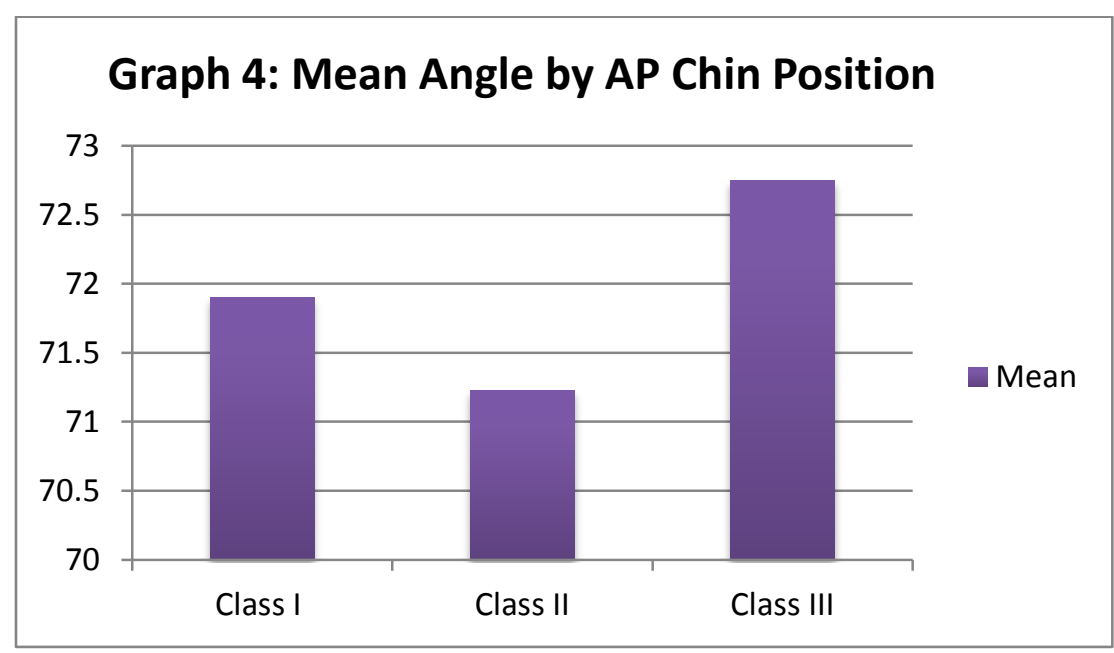

The ANOVA showed that there are significant differences between angle means at Class I, II, and III (P-value=0.0133). See table 7 and graph 4. 
Table 8 :Tukey Kramer Multiple Comparisons Test

Variable

Mean

Letters

Class I

71.904

$\mathrm{AB}$

Class II

71.231

B

Class III

72.75

$\mathrm{AB}$

The Tukey Kramer multiple comparison procedure showed that there are no significant differences between Class I and Class III; there are no significant differences between Class I and Class II; there are significant differences between Class II and Class III. See table 8.

\section{Table 9: Orthodontists vs Non-Orthodontists}

\begin{tabular}{lr} 
Variable & P-value \\
Class I & 0.69 \\
\hline Class II & 0.92 \\
\hline Class III & 0.86 \\
\hline
\end{tabular}

The ANOVA showed that at Class I, there are no significant differences between operators (orthodontist vs non-orthodontist)(P-value=0.69); At Class II, there is no significant differences between operators (P-value=0.92); At Class III there are no significant differences among operators $(\mathrm{P}-\mathrm{value}=0.86)$. See table 9.

\section{Table 10: Males vs Females}

\begin{tabular}{lr} 
Variable & P-value \\
Class I & 0.07 \\
Class II & 0.93 \\
Class III & 0.68 \\
\hline
\end{tabular}


The ANOVA showed that at Class I, there are no significant differences between males and females (P-value=0.07); At Class II, there are no significant differences between males and females (P-value=0.93); At Class III, there are no significant differences among males and females $(\mathrm{P}$-value=0.68). See table 10 .

\section{CHAPTER 5: DISCUSSION}

\section{Part 1: Finding FALL and Glabella Vertical}

The objective of part 1 included: 1.) Can judgment alone be used as a reproducible method of defining FALL (forehead anterior limit line), a frontal facial plane; 2.) Can the Facial Plane (FP) Gauge more accurately determine the FALL judgment; 3.) Can judgment alone be used as a reproducible method of defining Glabella Vertical, a frontal facial plane; 4.) Can the Facial Plane (FP) Gauge more accurately determine the Glabella Vertical judgment; 5.) Can judgments of FALL and Glabella Vertical be reproducible over time; 6.) Can different judges produce the same measurements for FALL and Glabella Vertical.

It has been found the 3 raters differ from one another with respect to mean levels of all measurements (F, FC, G, and GC). However, the inter-rater reliability coefficient at T1 and T2 indicated moderate to good reliability. A coefficient of 0.70 or greater represents an acceptable

level of reliability. ${ }^{48}$ The reason for this is that the differences among the raters are a much smaller magnitude than the variability among patients. Also based on the data, it has been found that it is comparable or better to use Glabella Vertical as your frontal plane compared to FALL.

The FP gauge is somewhat more reliable to use when determing a FALL judgment due to the location of the landmark (FA of the forehead) being located further away from the referent 
(FA of the maxillary central incisor). When using Glabella as your landmark, the FP gauge is just as reliable as judgment alone. This finding is expected due to the landmark's location being closer to the FA of the maxillary central incisor. These judges were all experienced and had prior training with making judgments of F, FC, G, and GC. It is possible that the FP gauge would be beneficial when first learning to make the judgments. Further research would be needed to test this assumption.

The intra-rater judgment was found to be reliable from $\mathrm{T} 1$ to $\mathrm{T} 2$ indicating that operators can reproducibility determine F, FC, G, and GC judgments over time in NHO. Other studies have found the reproducibility of NHO over time..$^{21,31,49}$ They found a strong correlation between natural head position and estimated natural head position (ENHP) for both photographs and cephalograms. It has been said that ENHP gives a more reliable reference line and more natural head position. ${ }^{21,30}$

Natural head position has also been found to be remarkably reproducible over time. Peng and Cooke ${ }^{30}$ found that the reproducibility after 15 years $\left(2.2^{\circ}\right)$ was smaller than after 5 years $\left(3.0^{\circ}\right)$. The short term reproducibility has been confirmed by other researchers as well. ${ }^{29,31,33}$ However, Ferrario found NHP to be highly variable and gender dependent. ${ }^{50}$

\section{Part 2: GALL at Glabella}

The objective of part 2 included: Can Glabella be used as an accurate landmark to locate GALL (goal anterior limit line) and be coined Glabella Vertical. The data showed that the null hypothesis of the mean of GALL to Glabella $=0$ was rejected with the mean $=-0.22 \mathrm{~mm}$ and a standard deviation of $0.485 \mathrm{~mm}$. Although there was statistical significance found, the mean is 
clinically insignificant. From a treatment standpoint, being within $+/-1 \mathrm{~mm}$ is acceptable. Andrews ${ }^{15}$ advocates taking your FALL judgment and relating it to the inclination of the forehead to determine the location of GALL. Based on this research, a Glabella Vertical measurement can be used instead of FALL and forehead inclination to determine the optimal position of maxillary central incisors. Therefore, Glabella Vertical can be used as a frontal reference plane. See figure 7. 
Figure 7: The Range of GALL to Glabella

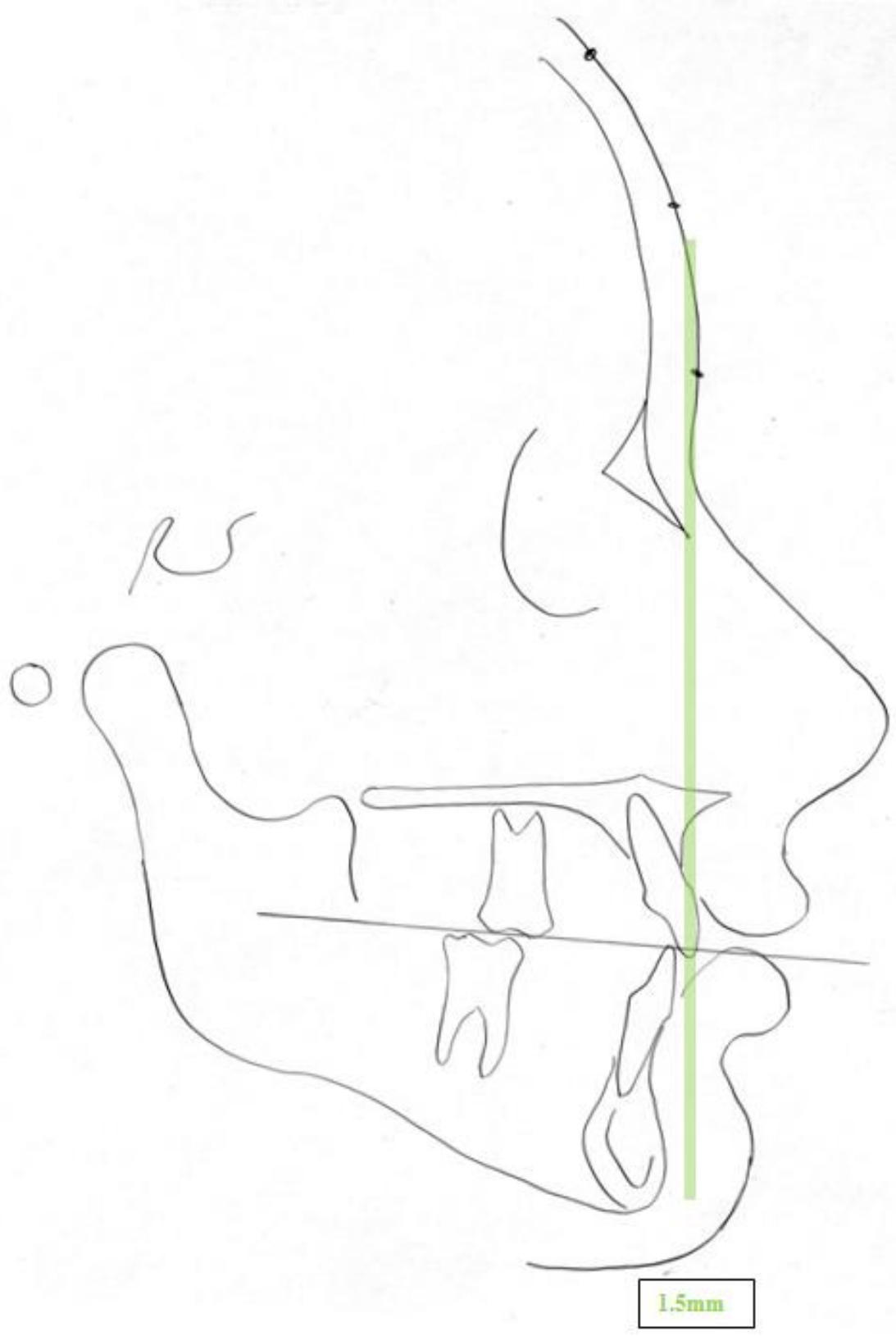

The GALL is located $-1 \mathrm{~mm}-0 \mathrm{~mm}$ from glabella in $95 \%$ of the population. The GALL is located $1.5-0 \mathrm{~mm}$ from glabella in $99.7 \%$ of the population. See figure 7. 


\section{Part 3: NHO in Relation to AP Chin Position}

Hedayati et $\mathrm{al}^{32}$ found that patients with a class III skeletal pattern had a more forward head posture compared to skeletal class I and II patients. Bjork and Marcotte demonstrated that

head position was more extended in class II and more flexed in class III. ${ }^{11,12}$ The objective of part 3 of this study included: Does mandibular AP chin position influence judgment of natural head orientation $(\mathrm{NHO})$.

This study shows that there are significant differences between the angle means at Class I, II, and III; therefore, the null hypothesis of the means being the same is rejected. The Tukey Kramer multiple comparisons procedure showed that there was no difference between Class I and Class III and no difference between Class I and Class II. However, there was statistical significance between Class II and Class III. Although there is a tendency for retrognathic AP chin positions to be judged in a slightly extended position and prognathic AP chin positions to be judged in a slightly flexed position, it is clinically insignificant due to the range of means being $1.52^{\circ}$. This translates to a difference of $+/-1 \mathrm{~mm}$ at the level of the central incisor. See figure 8 . 


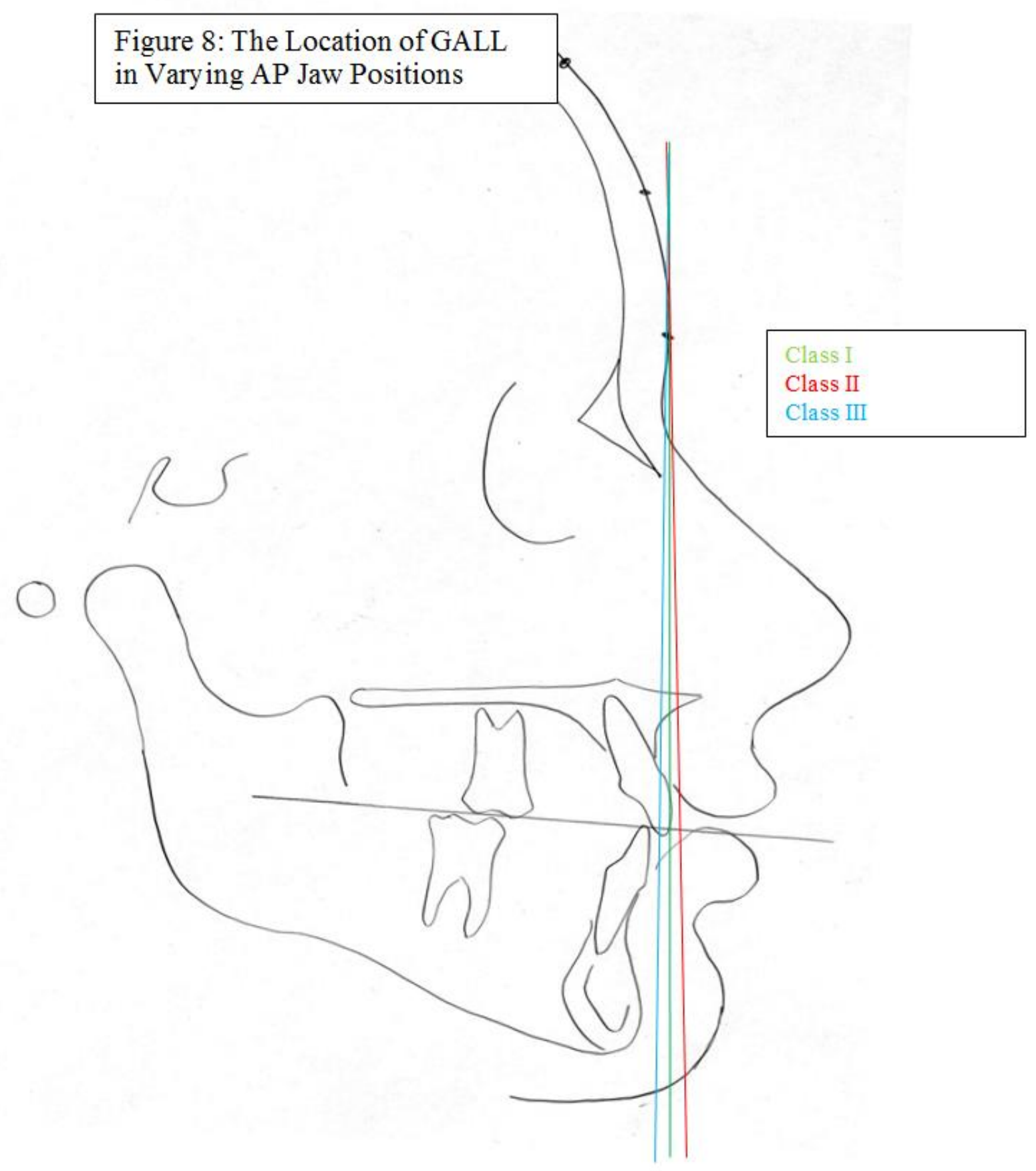


Another study supported that natural head position could be created with great reproducibility through orientation of profile images in different chin positions. ${ }^{40}$ They found that NHO is under the influence of chin position but that the influence was not clinically significant. This is in agreement with our study. However, Halazonetis and Odont ${ }^{38}$ found that NHO depended on chin position with protrusive chins being positioned more downward and retrusive chins positioned more upward.

The current study also found that there was no difference in judgment between males and females in judging NHO in class I, II, and III. Additionally, no differences were found between orthodontists and non-orthodontists. The non-orthodontists in this study were other dental professionals and staff members. They were all given instruction on NHO before completing the study. There may be a difference between orthodontists and non-orthodontists if no instruction was given.

\section{CHAPTER 6: SUMMARY AND CONCLUSIONS}

\section{Summary}

The objectives of this study included:

1. Can judgment alone be used as a reproducible method of defining FALL (forehead anterior limit line), a frontal facial plane

2. Can the Facial Plane (FP) Gauge more accurately determine the FALL judgment

3. Can judgment alone be used as a reproducible method of defining Glabella Vertical, a frontal facial plane

4. Can the Facial Plane (FP) Gauge more accurately determine the Glabella Vertical judgment 
5. Can judgments of FALL and Glabella Vertical be reproducible over time

6. Can different judges produce the same measurements for FALL and Glabella Vertical

7. Can Glabella be used as an accurate landmark to locate GALL (goal anterior limit line)

8. Does mandibular AP chin position influence judgment of natural head orientation (NHO)

The following null hypotheses were able to be rejected:

- Judgment alone of FALL is not a reliable method of defining a frontal facial plane

- The use of the Facial Plane (FP) Gauge is not a more reliable method than judgment alone to define FALL

- Judgment alone of Glabella Vertical is not a reliable method of defining a frontal facial plane

- Intra-operator reproducibility of FALL is not consistent

- Intra-operator reproducibility of Glabella Vertical is not consistent

The following null hypotheses were able to be accepted:

- The use of the FP Gauge is not a more reliable method than judgment alone to determine Glabella Vertical

- Inter-operator reproducibility of FALL is not consistent

- Inter-operator reproducibility of Glabella Vertical is not consistent

- GALL is not always located at glabella

- Mandibular AP chin position does not influence judgment of NHO 


\section{Conclusions}

The results of this study lead to the following conclusions:

1. Intra-rater judgment of FALL and Glabella Vertical is reproducible from one time point to another.

2. Inter-rater reliability is moderate-good at different time points.

3. It is comparable or better to use Glabella Vertical as your frontal plane compared to FALL.

4. If using FALL as your frontal plane, it is somewhat more reliable to use the FP gauge instead of judgment alone. This is expected since the landmark (FA of the forehead) is located further away from the FA of the maxillary central incisor.

5. When using Glabella Vertical as your frontal plane, the FP gauge is just as reliable as judgment alone. This is expected because the landmark (glabella) is located closer to the FA of the maxillary central incisor.

6. In this study, the judges were all experienced with making judgments of FALL and Glabella Vertical. It is possible that the FP gauge would be beneficial when first learning how to make the judgment. Further research is needed to test this assumption.

7. GALL is located $-1-0 \mathrm{~mm}$ from Glabella in $95 \%$ of people. Therefore, Glabella Vertical could be used as a frontal plane instead of FALL for diagnosis and treatment planning.

8. There is a slight tendency for prognathic chin positions to be judged in a flexed position and retrognathic chin positions to be judged in an extended position when determining NHO. However, it is not clinically significant because the range of means is $1.52^{\circ}$ which translates to $1 \mathrm{~mm}$ at the level of the FA point of the maxillary central incisor.

9. Orthodontists and non-orthodontists can both judge NHO the same. 
10. Males and females can both judge NHO the same.

\section{CHAPTER 7: SUGGESTIONS FOR FUTURE RESEARCH}

In part 1: Judgment of FALL and Glabella Vertical- there could be an increased: sample size for each group, number of judges, and time points. Also a comparision judgment of FALL and Glabella Vertical could be made from in vivo vs. photographs.

In part 2: Is GALL located at Glabella- an increased number of cephalograms could be traced and compared and also cephalograms could be obtained and traced from several different orthodontists that use Six Elements diagnosis.

In Part 3: Judging NHO in different chin positions- there could be an increased: number of operators, subjects to judge, and time points. Also a comparison judgment of NHO in vivo vs. photos could be determined. 


\section{REFERENCES}

1. Downs WB. Analysis of the dentofacial profile. Angle Orthod. 1956;26(4):191-212.

2. Bjehin R. A comparison between the frankfort horizontal and the sella turcica-nasion as reference planes in cephalometric analysis. Acta Odontologica. 1957;15(1):1-12.

3. Moorrees CF, Kean MR. Natural head position, a basic consideration in the interpretation of cephalometric radiographs. Am J Phys Anthropol. 1958;16(2):213-234.

4. Lundström F, Lundström A. Natural head position as a basis for cephalometric analysis. American Journal of Orthodontics and Dentofacial Orthopedics. 1992;101(3):244-247.

5. Moorrees CF. Natural head position—a revival. American Journal of Orthodontics and Dentofacial Orthopedics. 1994;105(5):512-513.

6. Cooke MS, Orth D. Five-year reproducibility of natural head posture: A longitudinal study. American Journal of Orthodontics and Dentofacial Orthopedics. 1990;97(6):489-494.

7. Cooke MS, Orth D, Wei SH. The reproducibility of natural head posture: A methodological study. American Journal of Orthodontics and Dentofacial Orthopedics. 1988;93(4):280-288.

8. Solow B, Tallgren A. Natural head position in standing subjects. Acta odontologica. 1971;29(5):591-607.

9. Huggare JÅ, Laine-Alava MT. Nasorespiratory function and head posture. American Journal of Orthodontics \& Dentofacial Orthopedics. 1997;112(5):507-511. 
10. Hellsing E, McWilliam J, Reigo T, Spangfort E. The relationship between craniofacial morphology, head posture and spinal curvature in 8, 11 and 15-year-old children. The European Journal of Orthodontics. 1987;9(1):254-264.

11. Björk A. Some biological aspects of prognathism and occlusion of the teeth. Acta Odontologica. 1950;9(1):1-40.

12. Marcotte MR. Head posture and dentofacial proportions. Angle Orthod. 1981;51(3):208-213.

13. Lundström A, Lundström F. The frankfort horizontal as a basis for cephalometric analysis. American Journal of Orthodontics and Dentofacial Orthopedics. 1995;107(5):537-540.

14. Andrews LF. The six keys to normal occlusion. Am J Orthod. 1972;62(3):296-309.

15. Andrews LF AW. Syllabus of the andrews orthodontic philosophy. U.S, 2001(Ninth ed).

16. Corruccini RS, Pacciani E. “Orthodontistry” and dental occlusion in etruscans. Angle Orthod. 1989;59(1):61-64.

17. Kingsley NW. A treatise on oral deformities as a branch of mechanical surgery. D. Appleton; 1880.

18. Proffit WR, Fields Jr HW, Sarver DM. Contemporary orthodontics. Elsevier Health Sciences; 2006.

19. Broadbent BH. A new x-ray technique and its application to orthodontia. Angle Orthod. 1931;1(2):45-66. 
20. Lundstrom A, Lundstrom F, Lebret LM, Moorrees CF. Natural head position and natural head orientation: Basic considerations in cephalometric analysis and research. Eur J Orthod. 1995;17(2):111-120.

21. Lundström F, Lundström A. Natural head position as a basis for cephalometric analysis. American Journal of Orthodontics and Dentofacial Orthopedics. 1992;101(3):244-247.

22. Subtelny J. A longitudinal study of soft tissue facial structures and their profile characteristics, defined in relation to underlying skeletal structures. Am J Orthod. 1959;45(7):481-507.

23. Nanda RS, Meng H, Kapila S, Goorhuis J. Growth changes in the soft tissue facial profile. Angle Orthod. 1990;60(3):177-190.

24. Park Y, Burstone CJ. Soft-tissue profile-fallacies of hard-tissue standards in treatment planning. American Journal of Orthodontics and Dentofacial Orthopedics. 1986;90(1):52-62.

25. Preston C, Evans W, Todres J. The relationship between ortho head posture and head posture measured during walking. American journal of orthodontics and dentofacial orthopedics. 1997;111(3):283-287.

26. Üsümez S, Orhan M. Inclinometer method for recording and transferring natural head position in cephalometrics. American journal of orthodontics and dentofacial orthopedics. 2001;120(6):664-670.

27. Chen C, Lai S, Tseng Y, Lee K. Simple technique to achieve a natural head position for cephalography. British Journal of Oral and Maxillofacial Surgery. 2008;46(8):677-678. 
28. Cuccia AM, Carola C. The measurement of craniocervical posture: A simple method to evaluate head position. Int J Pediatr Otorhinolaryngol. 2009;73(12):1732-1736.

29. Moorrees CF, Kean MR. Natural head position, a basic consideration in the interpretation of cephalometric radiographs. Am J Phys Anthropol. 1958;16(2):213-234.

30. Peng L, Cooke MS. Fifteen-year reproducibility of natural head posture: A longitudinal study. American Journal of Orthodontics and Dentofacial Orthopedics. 1999;116(1):82-85.

31. Lundstrom A, Forsberg CM, Westergren H, Lundstrom F. A comparison between estimated and registered natural head posture. Eur J Orthod. 1991;13(1):59-64.

32. Hedayati Z, Paknahad M, Zorriasatine F. Comparison of natural head position in different anteroposterior malocclusions. Journal of Dentistry of Tehran University of Medical Sciences. 2013;10(3):210-220.

33. Solow B, Tallgren A. Head posture and craniofacial morphology. Am J Phys Anthropol. 1976;44(3):417-435.

34. D'Attilio M, Epifania E, Ciuffolo F, et al. Cervical lordosis angle measured on lateral cephalograms; findings in skeletal class II female subjects with and without TMD: A cross sectional study. CRANIO®. 2004;22(1):27-44.

35. Vélez A, Restrepo C, PELÁEZ-VARGAS A, et al. Head posture and dental wear evaluation of bruxist children with primary teeth. J Oral Rehabil. 2007;34(9):663-670. 
36. Gonzalez HE, Manns A. Forward head posture: Its structural and functional influence on the stomatognathic system, a conceptual study. Cranio. 1996;14(1):71-80.

37. Festa F, Tecco S, Dolci M, et al. Relationship between cervical lordosis and facial morphology in caucasian women with a skeletal class II malocclusion: A cross-sectional study. Cranio. 2003;21(2):121-129.

38. Halazonetis DJ. Estimated natural head position and facial morphology. American journal of orthodontics and dentofacial orthopedics. 2002;121(4):364-368.

39. Halazonetis DJ. Morphometric correlation between facial soft-tissue profile shape and skeletal pattern in children and adolescents. American journal of orthodontics and dentofacial orthopedics. 2007;132(4):450-457.

40. Ahangar-Atashi M, Kachoei M. Effect of chin position on natural head orientation reproducibility. idea. 2011;3:7.

41. Kau C, Zhurov A, Scheer R, Bouwman S, Richmond S. The feasibility of measuring threedimensional facial morphology in children. Orthodontics \& craniofacial research. 2004;7(4):198-204.

42. Kau CH, Richmond S, Zhurov AI, et al. Reliability of measuring facial morphology with a 3dimensional laser scanning system. American journal of orthodontics and dentofacial orthopedics. 2005;128(4):424-430.

43. Cevidanes L, Oliveira AE, Motta A, Phillips C, Burke B, Tyndall D. Head orientation in CBCT-generated cephalograms. Angle Orthod. 2009;79(5):971-977. 
44. Weber DW, Fallis DW, Packer MD. Three-dimensional reproducibility of natural head position. American Journal of Orthodontics and Dentofacial Orthopedics. 2013;143(5):738-744.

45. Xia JJ, McGrory JK, Gateno J, et al. A new method to orient 3-dimensional computed tomography models to the natural head position: A clinical feasibility study. Journal of Oral and Maxillofacial Surgery. 2011;69(3):584-591.

46. Andrews WA. AP relationship of the maxillary central incisors to the forehead in adult white females. Angle Orthod. 2008;78(4):662-669.

47. Schlosser JB, Preston CB, Lampasso J. The effects of computer-aided anteroposterior maxillary incisor movement on ratings of facial attractiveness. American journal of orthodontics and dentofacial orthopedics. 2005;127(1):17-24.

48. Herzberg P. Principles of statistics. JOHN WILEY \& SONS, INC., 605 THIRD AVE., NEW YORK, NY 10158, USA, 1983, 544. 1983.

49. Jiang J, Xu T, Lin J. The relationship between estimated and registered natural head position. Angle Orthod. 2007;77(6):1019-1024.

50. Ferrario VF, Sforza C, Germano D, Dalloca LL, Miani Jr A. Head posture and cephalometric analyses: An integrated photographic/radiographic technique. American Journal of Orthodontics and Dentofacial Orthopedics. 1994;106(3):257-264. 
APPENDICES 


\section{Appendix A: IRB Approval}

\section{WestVriginiaUniversity. \\ Office of Research Integrity and Compliance}

\section{Approval Letter Expedited}

To

From

Approval Period

Subject

Protocol Number

Title
Timothy Tremont

WVU Office of Research Integrity and Compliance

08/08/2014 Expiration Date 08/07/2015

Protocol Approval Letter

1405291756

Facial planes as landmarks for diagnosis and treatment planning

The above-referenced research study was reviewed by the West Virginia University Institutional Review Board IRB and was approved in accordance with 46 CFR $46.101 \mathrm{~b}$.

It has been determined that this study is of minimal risk and meets the criteria as defined by the expedited categorys listed below:

- Category 4. Collection of data through noninvasive procedures not involving general anesthesia or sedation routinely employed in clinical practice excluding procectures involving $\mathrm{x}$-rays or microwaves. Where medical devices are employed they must be clearedapproved for marketing. Studies intended to evaluate the safety and effectiveness of the medical device are not generally eligible for expedited review including studies of cleared medical devices for new indications. Examples a physical sensors that are applied either to the surface of the body or at a distance and do not involve input of significant amounts of energy into the subject or an invasion of the subjects privacy b weighing or testing sensory acuity $c$ magnetic resonance imaging d electrocardiography electroencephalography thermography detection of naturally occurring radioactivity electroretinography ultrasound diagnostic infrared imaging doppler blood flow and echocardiography e moderate exercise muscular strength testing body composition assessment and flexibility testing where appropriate given the age weight and health of the individual.

- Category 5. Research involving materials data documents records or specimens that have been collected or will be collected solely for nonresearch purposes such as medical treatment or diagnosis.

Documents for use in this study have been approved and validated and are available in the WVUkc system in the Notes and Attachments section of your protocol.

Thank you.

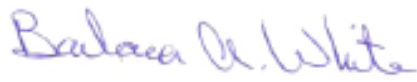

